Metacognitive control and lineup instructions:

Asking eyewitnesses to recollect reduces false identification

Nicola Guerin ${ }^{\mathrm{a} 1}$, Nathan Weber ${ }^{\mathrm{a}}$, and Ruth Horry ${ }^{\mathrm{b}}$

${ }^{a}$ Flinders University, School of Psychology,

GPO Box 2100, Adelaide, South Australia, 5001

${ }^{\mathrm{b}}$ Swansea University, Department of Psychology,

College of Human and Health Sciences, Vivian Tower, Swansea, SA2 8PP, UK

Acknowledgments: This research was supported by funding from the School of Psychology, Flinders University, and Australian Research Council Discovery Grant DP150101905 to N. Brewer, N. Weber, \& G. L. Wells.

Correspondence concerning this article should be addressed to Nicola Guerin, Cancer Council Victoria, 615 St Kilda Road, Melbourne, Victoria, 3004, Australia. Email: nicola.guerin@cancervic.org.au

\footnotetext{
${ }^{1}$ Now at Cancer Council Victoria, 615 St Kilda Road, Melbourne, Victoria, 3004, Australia
} 
Metacognitive control and lineup instructions: Asking eyewitnesses to recollect reduces false identification

\begin{abstract}
Little theoretically-informed research investigates how non-traditional lineup tasks or metacognitive instructions might improve eyewitness identification accuracy. We used a continuous dual-process model of recognition to explain familiarity-based identification errors and develop a modified lineup procedure that increased discriminability. In four studies using a multiple lineup paradigm we compared identification performance between lineup procedures featuring differing decision types (standard simultaneous, delayed-choice, elimination) and instructions (standard, metacognitive). Metacognitive instructions about how to better evaluate memory quality improved discriminability in delayed-choice but not standard or elimination lineups. With modified simultaneous lineup procedures, metacognitive instructions could potentially enable participants to use recollection more effectively and increase accuracy even when memory is poor. While immediate post-decision confidence is a good predictor of identification accuracy, lineup modifications that improve eyewitness memory use could provide more diagnostic evidence of probable guilt across a wider range of decisions. We discuss implications for lineup theory and design.
\end{abstract}

Keywords: eyewitness identification; feedback; recollection; metacognition; metamemory; recognition 
Eyewitness identification lineups play a key role in many criminal cases. Missed identifications are missed opportunities to gain evidence, while false positives can carry serious consequences for innocent suspects. The value of a lineup procedure rests on its diagnostic strength. However, witnesses, not independent experts, make the diagnoses, and witnesses hold preconceptions that can influence how effectively they use memory to make a lineup decision. Ultimately, a witness's metacognitive approach to a lineup limits its diagnostic strength, and inappropriate preconceptions can be detrimental to memory retrieval and evaluation, decreasing the reliability of identification decisions (e.g., Wixted, Mickes, Dunn, Clark, \& Wells, 2016). There is a pressing need to investigate better methods to harness eyewitnesses' cognitive capacities and increase the evidence value of lineup decisions. We extended a continuous dual-process model of recognition (Wixted \& Mickes, 2010) to lineups to develop a novel procedure designed to improve eyewitness use of memory and metacognitive monitoring in identification decisions.

\section{Identification bias}

Many eyewitnesses share the misconception that lineups are held to 'get the guy' and are biased toward making an identification rather than deciding the offender is absent (Wells, 1984). By neglecting critical qualities of retrieved memories that might indicate an identification is unwarranted (Palmer, Brewer, McKinnon \& Weber, 2010), biased eyewitnesses raise the risk of false identification for innocent suspects who resemble the offender.

A key feature of simultaneous lineups that may compound this effect is shared with associative recognition tasks: high similarity between previously-seen targets and the unstudied filler stimuli from which they must be differentiated. High target-filler similarity produces a sense of familiarity for unstudied fillers (Cook, Marsh, \& Hicks, 2005). While both familiarity and recollection can inform recognition (Wixted \& Mickes, 2010) in 
continuous dual-process accounts of associative recognition, participants who do not anticipate high target-filler similarity frequently focus only on familiarity and underestimate the need to effortfully recollect specific target details that might rule out an identification (i.e., recall-to-reject, Rotello \& Heit, 2002). Consequently, fillers are likely to be falsely recognised (Malmberg \& Xu, 2007). As standard simultaneous lineup procedures also feature high target-filler similarity and typically lack explicit procedural prompts (e.g., forced response lag: Malmberg \& Xu, 2007, cf Wixted \& Mickes, 2014) or instructions that would alert eyewitnesses that recollection is critical, eyewitnesses are likely to frequently neglect recollection. In simultaneous lineups, the closest match for the target must be discerned from multiple similar faces and evaluated. If the closest match is an innocent suspect who resembles the offender, mistaken identification is more likely when familiarity is not weighed against potentially mismatching details.

Further, Malmberg and Xu (2007) found that when associative recognition tests feature both high- and low-similarity fillers, participants made less use of recollection than when target-filler similarity was uniformly high. Typically, target-filler similarity is not uniform across lineup members and reviews of lineup similarity effects (e.g., Fitzgerald et al., 2015) and empirical tests of the 'dud effect' (Charman, Wells, \& Joy, 2011) demonstrate patterns like those found in associative recognition. That is, when simultaneous lineups include some fillers with relatively lower similarity to the offender, eyewitnesses mistakenly anticipate that distinguishing a guilty suspect will be relatively easy and are more likely to mistakenly identify an innocent suspect who closely resembles the offender than when targetfiller similarity is uniformly high. Dual-process models suggest that eyewitnesses neglect to recollect offender detail when not perceived to be necessary to rule out innocent lineup members, and rely on potentially misleading familiarity. We investigated the effectiveness of two task modifications that targeted these error-prone processes: 1) reconfigured lineup 
decision processes; and, 2) metacognitive instructions about recollection use (e.g., Lane et al., 2007).

\section{Modified Lineup Procedure}

In several models, simultaneous lineup decisions are made in two steps (Clark, 2003; Pozzulo \& Lindsay, 1999; Wixted et al., 2018). First, a best-match is found (best-match judgment). Second, the witness evaluates the match between the best-match and memory of the offender against a decision criterion and either identifies or rejects the best-match (offender-presence judgment). When finding the best-match, eyewitnesses can rely on relatively automatically retrieved familiarity, without considering recollected details. As recollection of details entails a higher cognitive load, particularly for weak memory traces, the need to recollect is frequently neglected if not perceived to be necessary (Malmberg \& $\mathrm{Xu}, 2007)$. Once familiarity-based recognition processes are established, eyewitnesses may continue to rely on familiarity to make the subsequent offender-presence judgment as they are not prompted to re-assess the recognition strategy to better fit the second judgment (Alban \& Kelley, 2012). Consequently, critical details that would counter the misleading familiarity of innocent lineup members are not retrieved. However, theoretically-based modifications to lineup decision structure could guide witnesses to effortfully recollect.

Sequential lineup procedures were developed to discourage similarity-based choosing (Wells, 1984). However, while sequential presentation can discourage overly liberal choosing (Palmer \& Brewer, 2012), it does not improve discriminability (Wixted et al., 2016), suggesting it does not improve recollection. In comparison, simultaneous presentation offers potential benefits for memory retrieval, such as multiple concurrent cues and the opportunity for comparisons that could highlight diagnostic features for evaluating guilt (Goodsell, Gronlund, \& Carlson, 2010; Wixted \& Mickes, 2014; Wixted, Vul, Mickes, \& Wilson, 2018). If familiarity-based responding could be pre-empted, these features of simultaneous 
presentation might maximise the effectiveness of modifications designed to encourage recollection. Hence, we modified standard simultaneous lineup procedure in our delayedchoice procedure.

Delayed-choice. When two consecutive recognition judgments of different types are not separated, participants tend not to recalibrate their recognition strategy for the second judgment, even when this would improve accuracy (Alban \& Kelley, 2012). Thus, separating best-match and offender-presence judgments might prompt eyewitnesses to use recollection to make their final identification decision, even if best-match selection had been familiaritybased. That is, when separately and explicitly prompted to evaluate whether the offender was or was not present, eyewitnesses might be more likely to retrieve evidence both for and against positive match. Pozzulo and Lindsay (1999) tested this idea in their elimination lineup, in which witnesses first selected the best-match and then indicated whether the bestmatch was the offender. However, these studies did not clearly show increased discriminability.

One possibility is that the elimination lineup did not improve memory use because neither eyewitness bias nor familiarity-based memory processes in the initial best-match judgment were countered, and simply separating the two judgments did not overcome their combined effect. One method to challenge these two factors is a reversed order of separated lineup judgments. That is, frontloading the offender-presence judgment and explicitly asking eyewitnesses to evaluate whether or not the lineup includes the offender, thereby delaying best-match selection and its propensity to encourage recollection neglect. Reversed judgment order re-frames the initial eyewitness task away from pick-the-best or find-the-guy strategies that rely on comparisons of positive match across lineup members and tend to encourage familiarity-based memory processes (Cook et al., 2005). Instead, the first lineup judgment would counter the common eyewitness bias to focus prematurely on the degree of positive 
match between lineup members and memory for the offender and highlight the need to evaluate memorial evidence both for and against a positive identification. With delayed bestmatch choice, and an explicit initial requirement to weigh up evidence for and against recognition, eyewitnesses might be more likely to effortfully attempt to recollect specific details to better evaluate positive match against potential mis-match (Johnson, Hashtroudi, \& Lindsay, 1993). Therefore, in the modified delayed-choice procedure, we separated and reversed the best-match and offender-presence judgments, requiring a separate response for each. Specifically, eyewitnesses first indicated whether they believed the offender was in the lineup (offender-presence judgment), then separately indicated which lineup member they believed to be the offender (if thought to be present)

While these modifications seemed promising, empirical evidence from multiple tasks suggests familiarity-based recognition is difficult to disrupt. Further, eyewitness bias to pick from the lineup is strong, and the delayed-choice procedure alone might not overcome this bias. Therefore, we also introduced metacognitive instructions shown to increase recollection and monitoring in other recognition tasks (Lane, Roussel, Villa, \& Morita, 2007). To our knowledge, this method had not previously been tested with lineups. Importantly, using metacognitive instructions with a delayed-choice order of lineup judgments meant instructions would not need to work against a strong initial procedural cue for familiaritybased processes (i.e., those used for best-match judgments). Therefore, we anticipated that separating and reversing the order of lineup judgments would maximise eyewitnesses' ability to apply metacognitive recognition instructions. This possibility was tested with the novel delayed-choice lineup.

Metacognitive Instructions. Recognition performance is affected by metacognitive task beliefs that vary in accuracy and task fit, and shape strategies for memory retrieval and monitoring (e.g., Gallo, 2004). Poor fit between task and metacognitive approach may lead to 
inappropriate or suboptimal decision-making strategies (Lane et al., 2007; Malmberg \& Xu, 2007). For example, over-estimating the likelihood of offender-presence in a lineup encourages an overly liberal identification criterion (Clark, 2005). However, simply informing participants about task features without explaining their implications for memory use does not consistently improve memory retrieval and monitoring (Gallo, 2004). In the case of lineups, unbiased instructions that the culprit may or may not be in the lineup encourage more conservative decision-making, without improving memory use to increase discriminability (Clark, 2005; Mickes et al., 2017). However, providing information that aligns metacognitive knowledge of memory processes with task requirements can effectively improve recognition (e.g., Starns, Lane, Alonzo, \& Roussel, 2007) and similar instructions might improve discriminability in lineups.

Metacognitive instructions based on dual-process recognition models improve recollection via two key mechanisms: recollection retrieval and monitoring memory quality (Lane et al., 2007). Instructions that are potentially useful for lineups feature two types of information (Blank \& Launay, 2014; Lane et al., 2007): task-related information about common memory errors (e.g., familiarity-based false identification); and information highlighting critical phenomenological markers of memory accuracy (e.g., vividness and clarity). These instructions increase recollection and decrease false recognition in various tasks (e.g., Lane, Roussel, Starns, Vila, \& Alonzo, 2008). Therefore, we expected them to improve recollection in lineups, especially when used with the delayed-choice procedure.

Providing procedural task-related information can improve performance when preconceptions typically divert participants from using memory processes crucial for accuracy (Gallo et al., 2001). While task-related instructions are most effective when given before encoding (Gallo, 2010) they can also be effective when given at retrieval (Starns et al., 2007). For example, informed participants can switch attention to source memory after 
receiving misinformation (Johnson et al., 1993), and make better use of recollection in associative recognition (Gallo, Roediger, \& McDermott, 2001; Starns et al., 2007). For lineups, this is crucial, as test instructions necessarily follow crime exposure.

Effective task-related instructions refer more directly to memory processes (e.g., misleading similarity) and specific metacognitive action (e.g., attention to memory source, or effortful recollection) than standard unbiased lineup instructions that are more abstract and do not explain how to avoid memory errors. Therefore, while unbiased lineup instructions generally encourage more conservative response bias, providing specific task-related information about potential errors may preferentially reduce false identifications and increase discriminability (Blank \& Launay, 2014; Higham, Blank, \& Luna, 2017). Following taskrelated instructions shown to be effective in associative recognition (Lane et al., 2007; 2008), we informed participants about target-filler similarity, familiarity-based decision-making, and recollection.

While task-related instructions alone have been shown to effectively increase discriminability in tasks featuring high target-filler similarity, phenomenological information often contributes to their effect (Lane et al., 2007; 2008). Phenomenological information directs attention to memory qualities that are indicative of accurate remembering: relative vividness, clarity, and detail (Mather, Henkel, \& Johnson, 1997). Participants attending to these qualities differentiate more accurately between true and false recognition even when false recognition is subjectively compelling (Schooler, Gerhard, \& Loftus, 1996). By highlighting the diagnostic value of these qualities, phenomenological instructions reduce false recognition, and have been effective in tasks for which task-related instructions were not useful (Lane et al., 2007). Consequently, as a starting point, we included both task-related and phenomenological information in our metacognitive instructions. 


\section{The Experiments}

In four face-recognition lineup experiments, we tested metacognitive instructions in standard and modified simultaneous lineups. Participants studied multiple targets and made identification decisions about a four-person lineup for each. This paradigm allowed collection of multiple data points per participant and stimulus to increase statistical power and initial generalisability, and lineup accuracy and response strategies have been shown to remain stable over multiple trials (Mansour et al., 2017). Alternative single lineup paradigms limit generalisability and require large samples, so their ecological validity is more valuable at a later stage of procedural development.

In the standard lineup procedure, participants either made a positive identification or indicated that the target was not present. In the delayed-choice procedure, participants first indicated whether the target was in the lineup before, in a separate decision, identifying the target (if thought present). The procedures were tested with and without metacognitive instructions, refined over the course of the experiments.

We had three major research questions. First, would the delayed-choice procedure increase discriminability? We expected that separating and reversing component lineup judgments would decrease the likelihood of false identification by encouraging recollection and thereby increasing discriminability. Second, would metacognitive instructions improve discriminability? We predicted that metacognitive instructions would increase retrieval and monitoring of recollection to improve discriminability. Third, would metacognitive instructions be more effective in delayed-choice than standard simultaneous lineups? We predicted that participants completing delayed-choice lineups would gain less benefit from metacognitive instructions than those completing standard lineups and therefore show greater improvement in discriminability. 


\section{Experiment 1}

We first compared the standard lineup with two variants of the delayed-choice lineup: one with, and one without metacognitive instructions. We predicted greater discriminability in the delayed-choice lineups than the standard lineup, and greater discriminability in the delayed-choice lineup with metacognitive instructions than without.

\section{Method}

Design. We used a 3 (lineup type: standard; delayed-choice; delayed-choice with instructions) $\times 2$ (target presence: target-present; target-absent) mixed experimental design. Lineup type was varied between-subjects and target-presence within-subjects. Lineup decisions and response latencies were recorded.

Participants. We aimed to collect data from 30 participants per condition to achieve adequate power to test hypotheses with mixed-effects regression models (Judd, Westfall, \& Kenny, 2017). Undergraduate students participated for payment or course credit and 93 students (65 female, age: $M=23.30, S D=6.56$ years) participated. All collected data were analysed.

Materials. Forty sets of five description-matched colour photos were used. Photos showed a front view of the head and neck with neutral facial expression and background (200 $\times 200$ pixels) and were presented on an 18 " monitor (resolution: $1920 \times 1080$ pixels). Each set included a randomly designated target (identical at study and test), target-replacement (for target-absent lineups), and three fillers. Sets were split into two blocks of 20. In each block, half of the trials were target-present and half target-absent. Lineups were presented as a horizontally centred row of four photos with response buttons below. A text cue (name or occupation, by block) centred horizontally above photos was presented with each target (study) and lineup (test). Photo order in lineups, trial order in blocks, cue and target-presence 
assignment, were randomly determined for each participant. Name cue randomisation was constrained by gender.

Procedure. After giving informed consent, participants completed the experiment in individual cubicles using a mouse to click on-screen buttons in response to written prompts. After four practice trials, participants completed two blocks of trials. Block order and cue type (name or occupation) were counterbalanced. Blocks included a study phase, a threeminute spatial memory distracter task, and a test phase.

In each study phase, participants studied 20 targets. In each trial, following previously established exposure times, a cue (name or occupation) appeared on the screen for $1000 \mathrm{~ms}$ before a target photo appeared, and target and cue remained on screen for a further $1000 \mathrm{~ms}$.

In each test phase, participants completed 20 trials. At the beginning of the test phase, participants were instructed that lineups may or may not include a target. In the standard lineup condition, participants provided a single response to each lineup, either identifying a lineup member by clicking on a photograph or rejecting the lineup by clicking the Not Present button. In the delayed-choice lineup conditions, participants provided two identification responses to each lineup and were informed about both decisions at the beginning of the test phase to approximate realistic conditions (i.e., the expectation that a present offender will be identified). First, for each lineup, participants indicated whether the target was Present or Not Present, without selecting any individual lineup member. After this decision was made for all lineups in the block, each lineup indicated to include a target was presented again in identical order. For each lineup, participants selected the face they believed was the target. The test block was structured in this way to minimise the impact of the decision strategy adopted for best-match selection from influencing the strategy adopted for the offender-presence judgment for the following lineup. 
In the delayed-choice with instructions lineup condition, participants received additional task-related and phenomenological information before each test block (see supplementary materials for full instructions). Instructions were based on exemplars effective in other recognition memory tasks (Gallo, 2010; Lane et al., 2007; 2008; Schooler et al., 1986; Starns et al., 2007). Participants were given task-related information that lineups were description-matched, leading to high target-filler similarity but including some relatively less similar fillers. They were further told that previous research showed that due to high lineup similarity “...people sometimes mistakenly decide that the studied face is present when all four photographs show faces that have not been studied. When people focus on the similarity between test faces and the studied face, they pay less attention to evidence that the test faces are not the studied face." We gave participants phenomenological information that relatively clear, vivid memories, with recollected detail, are diagnostic of accuracy: "Research has shown that accurate decisions about the studied face being present are likely to be accompanied by more vivid and clear memories of studying the face than when an unstudied test face is inaccurately and mistakenly recognised. These can include memories of how the studied face looked, memories of how the nameloccupation and the studied face are related, and other thoughts and feelings that were experienced when the face was studied."

Phenomenological information was repeated when participants were instructed (before each test block and again midway) to use the information to improve the accuracy of their lineup judgments "to avoid mistakenly and inaccurately recognising a test face that is similar to the studied face but was not studied.”.

Following the final test phase, participants completed manipulation check questions tested recall of instructions and self-reported decision-making including three open-ended 
items, one option-ranking item, and 17 items with 7-point Likert response scales (complete questionnaire included with supplementary materials) ${ }^{2}$.

\section{Results and Discussion}

Overview and measures. We used an alpha level of .05. Aggregate descriptive statistics for identification responses, signal detection measures of discriminability $\left(d^{\prime}\right)$ and response bias $(C)$, and Cohen's $d$ for key comparisons of discriminability, are shown in Table 1 (see also Figure 1). For datasets including multiple participants' responses to multiple stimuli, analyses of aggregate measures can be biased and not appropriately account for shared variability (Judd, Westfall, \& Kenny, 2012). Therefore, planned comparisons of response bias and discriminability were made in mixed-effects logistic regression models predicting choosing or 'suspect' (target or target-replacement) identifications. These models are equivalent to variance (ANOVA) models of aggregate measures of response bias (e.g., $C$ ) and discriminability (e.g., $d^{\prime}$ ) respectively (Wright \& London, 2009), as described below.

The main outcome measures were 'suspect' identifications (of targets or targetreplacements), and overall choosing (identification of any lineup member). The key predictors (fixed factors) were lineup type and the lineup type $\times$ target-presence interaction term. In models predicting suspect identifications, the coefficient for the fixed factor of target-presence indicates discriminability (i.e., the difference in the likelihood of identifying the 'suspect' between target-absent and target-present lineups). The lineup type $\times$ targetpresence interaction coefficient therefore indicates a difference in discriminability between lineup conditions. Finally, the lineup type coefficient indicates a difference between lineup

\footnotetext{
${ }^{2}$ We did not measure decision confidence or use ratings of familiarity or recollection in these experiments for two reasons. First, decision confidence for different recognition responses would not be directly comparable. Second, we wanted to avoid any effect of providing decision confidence or familiarity and recollection ratings on participants' metacognitive approach to test lineups in the multiple trial paradigm.
} 
conditions in response bias, or the overall tendency to make a positive identification, if there is no interaction with target presence.

In models predicting overall choosing (including filler selections), we evaluated differences in patterns of suspect and filler identifications between lineup conditions. As filler identifications are largely familiarity-based (i.e., resulting from target-filler similarity), differences in patterns of filler identification between lineup conditions can provide a useful indication of whether greater discriminability for a lineup condition indicates greater overall accuracy (e.g., as a result of better recollection), or a different pattern of errors (e.g., a greater proportion of filler selections). For models predicting overall choosing, the lineup type coefficient indicates a difference between lineup conditions in the likelihood of a positive identification decision. The lineup $\times$ target-presence interaction coefficient indicates a difference between lineup conditions in patterns of choosing across target-absent and targetpresent lineups.

The coefficient for a predictor in logistic regression indicates the log odds ratio $(\ln O R)$ of the outcome, and odds ratios $(O R)$ indicate effect size. For significant effects, the $95 \%$ confidence interval around the coefficient $\left(95 \% \mathrm{CI}_{b}\right)$ excludes 0 . Random effects and model fit statistics are reported in supplementary materials. Data were analysed using the lme4 package (Bates, Maechler, Bolker, \& Walker, 2014) for R (R Core Team, 2014) ${ }^{\mathrm{i}}$.

\section{Analysis}

Comparison of standard lineups and delayed-choice lineups. In models predicting suspect identifications, there was no significant difference in response bias $\left(O R_{\text {lineup }}=0.79\right)$ or discriminability $\left(O R_{\text {lineup }} \times\right.$ target presence $\left.=0.64\right)$, though response bias tended to be more conservative for delayed-choice lineups, and a similar pattern was observed in models 
predicting choosing overall (Table 2, Figure 2). Thus, the delayed-choice procedure did not significantly improve the discrimination of targets from target-replacements.

We found no supporting evidence for our hypothesis that the delayed-choice procedure would encourage recollection. It was possible that recollection was improved in the first offender-presence judgment, but that the multiple lineup paradigm then led to lower accuracy in later best-match selection by increasing the potential for interference across trials from multiple lineup exposures. If familiarity-based strategies were then adopted for the bestmatch task, and source memory neglected, an improvement in first-decision accuracy might be lost. Consistent with this possibility, the trend to fewer target identifications in the delayed-choice condition was accompanied by more incorrect filler identifications from target-present lineups in the best-match judgment, rather than more incorrect lineup rejections in the offender-presence judgment (see Table 1). That is, accuracy was greater across first offender-presence judgments, but not best-match judgments. Importantly, interference would not occur in a single trial identification paradigm or real setting, therefore we cannot rule out the possibility that delayed-choice lineups without metacognitive instructions might be effective in a more ecologically valid task, and this remains to be tested. However, in the present experiment, if metacognitive instructions successfully prompted greater recollection for both judgments, including retrieval of source memory, interference would have less impact on overall accuracy.

Comparison of standard lineups and delayed-choice lineups with instructions. We predicted less familiarity-based decision-making and higher discriminability in the delayedchoice procedure with instructions than in standard lineups (without instructions). Manipulation checks in all experiments were generally consistent with participants attending to instructions (see supplementary materials). We found significantly more conservative response bias in delayed-choice lineups with instructions than in standard lineups for models 
predicting suspect identifications $\left(O R_{\text {lineup }}=0.41\right)$ and those predicting overall choosing $\left(O R_{\text {lineup }}=0.41\right)$, with no significant differences in discriminability (Table 2, Figure 2$)$. In sum, memory use was not significantly better in the delayed-choice procedure with metacognitive instructions than in standard lineups.

\section{Comparison of delayed-choice lineups with and without instructions. Comparing} suspect identifications, we found significantly higher discriminability for delayed-choice procedures with instructions than without instructions $\left(O R_{\text {lineup } x \text { target-presence }}=2.16\right.$, Table 2 , Figure 2). As shown in Table 1, the proportion of accurate target identifications was higher, and participants avoided false identifications more effectively when metacognitive instructions were provided with the delayed-choice procedure than when they were not. This finding is notable given the observed trend to more conservative responding in both delayedchoice lineup conditions compared with standard lineups. Even with this lower risk of false identification, metacognitive instructions reduced the risk further.

Looking at overall choosing, we found significantly more conservative responding when metacognitive instructions were provided with the delayed-choice procedure than when they were not $\left(O R_{\text {lineup }}=0.53\right.$, Table 2 , Figure 2$)$, but there were no other significant effects. As shown by the descriptive statistics in Table 1, filler identifications were reduced particularly from target-present lineups when instructions were given, leading to greater target identification accuracy than when instructions were not provided. Instructions thus enabled participants to make better use of memory in both offender-presence and best-match judgments, especially when cued by the presence of the target (Guerin, Robbins, Gilmore, \& Schacter, 2012). Thus, if participants tended to adopt familiarity-based recognition strategies for the best-match judgment in the delayed-choice procedure without instructions, this was countered effectively by providing metacognitive instructions. However, metacognitive 
instructions also significantly reduced choose overall, resulting in a higher cost of missed target identifications despite lower false identification risk.

\section{Experiment 2}

Eyewitness identification studies show that unbiased lineup instructions and warnings against false identification that do not explain how to avoid the error lead to more conservative responding (Mickes et al., 2017). Task-related instructions used in Experiment 1 may have produced a similar effect, overshadowing the potential benefit of phenomenological information. Therefore, we cut task-related elements.

We replicated the between-subjects comparison of delayed-choice and standard lineups from Experiment 1 and added within-subjects tests of revised metacognitive instructions for both lineup types. Participants completed 40 test trials in either the standard or delayedchoice condition, then a further 40 test trials with instructions in the same lineup type. All participants completed blocks in this order as the instructions manipulation could not be counterbalanced without risking carryover of instructional benefits from earlier to later blocks. Additional lineups increased stimulus variability and generalisability. In additional face-sets, target appearance varied from study to test, providing a stronger test of manipulations, and addressing a limitation of Experiment 1 in that faces photos did not vary between study and test, and might therefore have tested picture memory rather than face memory.

\section{Method}

The method was as in Experiment 1, except as indicated.

Design. The experiment followed a 2 (lineup type: standard; delayed-choice) $\times 2$ (instructions: instructions, standard) $\times 2$ (target-presence: target-present, target-absent) mixed 
design. Lineup condition was varied between-subjects, with target-presence and instructions manipulated within-subjects.

Participants. We aimed to test 30 participants per between-subjects condition. The final sample included 64 participants (47 female, age: $M=21.97, S D=6.11$ years).

Materials. We used the original collection of lineups and a second collection of 40 sets constructed using the same method. In new lineups, test photos of targets varied from study photos, making face recognition more challenging, more strongly testing modified procedures, and approximating the encoding-test variability experienced by real eyewitnesses. At test, target photos showed a front view of the head and neck with neutral facial expression. However, target photos at study showed either a front view of the head and neck with a different facial expression (smiling), or a three-quarter view of the head and neck with neutral expression.

Procedure. After giving informed consent, participants completed four blocks of 20 trials. The procedure was identical to Experiment 1, except for the revised metacognitive instructions which were manipulated within-subjects. In the first two blocks, participants received standard unbiased lineup instructions. Then, before the third and fourth test phases, all participants received metacognitive instructions. These revised metacognitive instructions were identical to the phenomenological instructions from Experiment 1 and excluded taskrelated information. Participants were instructed avoid similarity-based positive identification, but only by using phenomenological information to make accurate identification decisions: "If you think the test photograph is similar to your memory for the studied face, but your memory is not clear, vivid or detailed, you should response Not Present." 


\section{Results and Discussion}

Comparison of standard lineups and delayed-choice lineups. We first compared response patterns across lineup conditions using only blocks completed without metacognitive instructions and found no significant differences in response bias or discriminability (Tables $3 \& 4$, Figure 3 ). However, in each model, the lineup coefficient was not trivial, and CIs included values largely below zero, suggesting a tendency to more conservative response bias with delayed-choice than standard lineups, as in Experiment 1.

\section{Comparison of standard lineups and delayed-choice lineups with instructions.}

Responding was significantly more conservative in delayed-choice lineups with instructions than in standard lineups, as seen in both the suspect identification model $\left(O R_{\text {lineup }}=0.41\right)$ and in the overall choosing model $\left(O R_{\text {lineup }}=0.39\right.$, see Table 4, Figure 3). However, discriminability did not differ significantly, providing no support for the hypothesis that delayed-choice lineups with revised instructions would elicit better memory use than standard lineups.

Comparison of delayed-choice lineups with and without instructions. Participants completing delayed-choice lineups with instructions were also significantly less likely to make an identification (accurate or not) than when they had not been given metacognitive instructions. This was true for both suspect identifications $\left(O R_{\text {lineup }}=0.50\right)$ and overall choosing $\left(O R_{\text {lineup }}=0.58\right)$. However, consistent with Experiment 1 , there was a trend to higher discriminability in delayed-choice lineups with instructions (Table 4, Figure 3, see also Figure 1). While the effect was not significant, the coefficients were substantial for both models (suspect identifications: $O R_{\text {lineup }} \times$ target-presence $=1.63$; choosing: $O R_{\text {lineup }} \times$ target-presence $=$ 1.34), with CIs biased strongly toward values falling above 0 . When participants in the delayed-choice condition were given metacognitive instructions, they tended to be better able 
to differentiate between targets and non-targets, although the effect did not reach statistical significance. Notably, the effect was within-subjects, meaning instructions tended to improve memory use even after participants had earlier used less optimal decision-making in trials completed without instructions. While practice effects were a potential threat (as we could not sensibly counterbalance instructions conditions), there was no equivalent effect of instructions in standard lineups.

Comparison of standard lineups with and without instructions. In models predicting suspect identifications, discriminability was significantly lower with metacognitive instructions than without $\left(O R_{\text {lineup }} \times\right.$ target-presence $\left.=0.46\right)$. Models predicting choosing revealed that responding was significantly more conservative overall with metacognitive instructions than without for participants completing standard lineups $\left(O R_{\text {lineup }}=0.55\right.$, Table 4 , Figure 3$)$. Thus, metacognitive instructions in standard lineups reduced discriminability and choosing. As the effects of the metacognitive instructions were qualitatively different for standard than delayed-choice lineups, this was unlikely to be a practice effect. Instead, this finding suggests that unless lineup procedures are restructured to encourage recollection, metacognitive instructions might be counter-productive.

\section{Experiment 3}

In Experiments 1 and 2, we found a trend to higher discriminability in delayed choice procedures with metacognitive instructions than in standard lineups, but the effect was not statistically significant. Therefore, in a third experiment we further revised metacognitive instructions to remove all remaining references to lineup similarity and false identification, including only phenomenological information. In Experiment 3, lineup type was varied between-subjects on three levels: standard lineup; standard lineup with instructions; and delayed-choice lineup with instructions. Comparing standard lineups with and without 
metacognitive instructions in a between-subjects design allowed us to test whether the conservative shift in response bias in Experiment 2 was due to order or practice effects, or due to the instructions.

\section{Method}

Design. Experiment 3 followed a 3 (lineup type: standard lineup; standard lineup with instructions; delayed-choice lineup with instructions) $\times 2$ (target-presence: target-present, target-absent) mixed design. Lineup type was varied between-subjects and target-presence was manipulated within-subjects.

Participants. We again aimed to recruit 30 participants per between-subjects condition, and tested 96 participants (79 female, age: $M=23.27, S D=8.22$ years).

Materials. The stimuli were identical to Experiment 2.

Procedure. Metacognitive instructions were identical to those provided in Experiment 2, except the explicit instruction to avoid similarity-based identifications was removed (i.e., "If you think the test photograph is similar to your memory for the studied face, but your memory is not clear, vivid or detailed, you should response Not Present."). The procedure for the standard lineup conditions was identical to that in Experiment 2, except that in the standard lineup with instructions condition, participants received revised metacognitive instructions. The procedure in the delayed-choice with instructions condition was identical to the delayed-choice condition in Experiment 2, except for the revised content of metacognitive instructions.

\section{Results \& Discussion}

\section{Comparison of standard lineups (without instructions) and delayed-choice lineups}

with instructions. Discriminability was significantly higher for delayed-choice lineups with 
instructions than standard lineups in both the suspect identification model $\left(O R_{\text {lineup }} \times\right.$ target presence $=1.70)$ and the overall choosing model $\left(O R_{\text {lineup }} \times\right.$ target-presence $=1.55$; Tables $5 \& 6$ and

Figure 4, see also Figure 1). Further examination of response patterns showed that false identification was significantly less likely in delayed-choice lineups with instructions than in standard lineups, (odds of false identification Delayed-choice with instructions $=0.33$; odds Standard $=$ 0.67), but without a significant difference in correct target identifications (odds Delayed-choice with instructions $=1.70$; odds Standard $=2.23$ ). Thus, higher discriminability was not accompanied by more conservative responding overall. Rather, as predicted, witnesses made significantly better use of memory when given revised metacognitive instructions with the delayed-choice procedure than in standard lineups.

Comparison of standard lineups with and without instructions. In stark contrast, providing revised metacognitive instructions in standard lineups had no significant effect on either response bias or discriminability when compared with standard lineups completed without metacognitive instructions (false identifications, $O R=1.00$; target identifications, $O R$ $=0.96$, see Table 6 )

\section{Summary of Results for Experiments 1-3}

Contrary to evidence from recognition memory paradigms (e.g., Blank \& Launay, 2014; Gallo, 2010; Starns et al., 2007), task-related information highlighting lineup mechanics did not scaffold better memory use. Rather, metacognitive instructions were effective when they included only phenomenological information. In Experiment 3, providing phenomenological metacognitive instructions with a delayed-choice lineup procedure facilitated more effective discrimination of targets from target-replacements than in standard simultaneous lineups without instructions. Consistent with continuous dual-process accounts of familiarity-based recognition (Wixted \& Mickes, 2010), our results show that countering best-match decision-making and encouraging better use of recollection improved 
identification reliability. However, neither the delayed-choice lineup or phenomenological metacognitive instruction improved discriminability in isolation. Only in combination did these modifications reframe participants' metacognitive approach to improve memory use.

\section{Experiment 4}

To further test the dual-process explanation, we tested the metacognitive instructions from Experiment 3 with the elimination lineup developed by Pozzulo \& Lindsay (1999). In elimination lineups, best-match and offender-presence judgments are made separately, however, in contrast to our delayed-choice procedure, the order of judgments is not altered. The elimination lineup does not address the problem of familiarity-based best-match selection, and previous studies in an identification paradigm have not provided strong evidence of improved memory use in the offender-presence decision when judgments were separated without further modification, giving eyewitnesses the opportunity to reassess their decision strategy for the second judgment. However, if the elimination lineup (without metacognitive instructions) increased participants' use of recollection in the offenderpresence judgment, we would expect higher discriminability than in standard lineups.

We have reasoned that metacognitive instructions would be less effective when given with lineup procedures promoting familiarity-based responding (i.e., standard simultaneous lineups) than with procedures promoting recollection. Our results from Experiment 3 supported this hypothesis. However, if the elimination procedure also facilitated use of metacognitive instructions, combining them would also be expected to produce higher discriminability than when no instructions were provided.

\section{Method}

Design. The experiment followed a 3 (lineup type: standard lineups; elimination lineups; elimination lineups with instructions) $\times 2$ (target-presence: target-present, target- 
absent) mixed design. Lineup type was varied between-subjects, and target-presence withinsubjects.

Participants. As in previous experiments, we aimed to recruit 30 participants per condition. In all, 112 students ( 87 female, age: $M=23.13, S D=6.99$ years) completed Experiment 4.

Materials. We used the lineup sets from Experiment 1.

Procedure. The procedure for the standard lineup condition was identical to Experiment 1. In the elimination lineup conditions, participants gave two responses for each lineup. For each test trial, participants first clicked on the lineup member that best matched the studied face. Once selected, remaining faces disappeared from the screen, leaving the best-match on screen for an additional $1500 \mathrm{~ms}$ before response options for the second judgment appeared also appeared. For the second judgment, participants indicated whether the face on screen was the target (Yes; No). Participants completing elimination lineups without metacognitive instructions were given standard unbiased lineup instructions. Participants completing elimination lineups with instructions were given the metacognitive instructions used in Experiment 3.

\section{Results and Discussion}

We found no significant difference in response bias or discriminability in models predicting suspect identifications or choosing overall when comparing i) standard lineups and elimination lineups; ii) standard lineups and elimination lineups with instructions; or iii) comparing elimination lineups with instructions and elimination lineups without instructions (Tables $7 \& 8$, Figure 5). In sum, there was no evidence that separating judgments in the elimination lineup improved the quality of lineup decision-making or facilitated an effect of metacognitive instructions. 
The elimination lineup may not be effective in encouraging recollection for two key reasons. First, though the best-match and offender-presence judgments were separated, the initial comparative best-match judgment is likely to orient witnesses towards evaluating positive familiarity-based match between a memory trace and lineup members, and discourage effortful recollection of specific details that would help to rule out a false identification when the offender is not present (Johnson et al., 1993). Second, the crucial offender-presence judgment is made while the best-match is presented in isolation, reducing the ability to compare lineup members to identify diagnostic identity cues (Wixted \& Mickes, 2014).

\section{General Discussion}

We extended a continuous dual-process model of recognition (Wixted \& Mickes, 2014) to simultaneous lineups to explain the effects of task structure and eyewitness metacognition on identification decision-making. In this account, eyewitness bias to choose from the lineup is associated with over-reliance on familiarity and neglect of critical recollection that might protect against false identification. We developed a modified lineup procedure (hereafter the recollection lineup) featuring two key components: 1) delayed-choice decision structure; and 2) metacognitive instructions about memory phenomenology. In testing the procedure, we made two key findings: first, the recollection lineup reduced false identification from simultaneous lineups without significantly reducing accurate identification, thereby increasing discriminability; and, second, eyewitness memory can be enhanced with metacognitive instructions. Participants using the delayed-choice decision structure were able to use metacognitive instructions about the qualities of accurate remembering to discriminate more effectively between studied and unstudied faces, demonstrating a similar contribution of metamemory as in other recognition tasks. 
We also found evidence of the type of metacognitive instructions for recollection that effectively increased discriminability in lineups: phenomenological information about the qualities of accurate memories (i.e., relatively greater vividness, clarity, and detail). In contrast, providing detailed task-related information (e.g., about lineup structure) led only to more cautious choosing, perhaps by heightening awareness of false identification risk without changing memory processing. Importantly, phenomenological information increased discriminability only with the delayed-choice procedure designed to counter familiarity-based processing, not with elimination or standard simultaneous procedures.

Taken together, these findings are consistent with the idea that the familiarity-based processing characteristic of best-match-first simultaneous lineup procedures is resistant to intervention, and eyewitnesses tend to neglect recollection. Further, phenomenological instructions to increase recollection are only effective in procedures that otherwise counter familiarity-based decision-making. While it is possible participants simply did not attend to 'common-sense' phenomenological information when relatively novel task-related information was also included in instructions (e.g., Kahnemann, 2011), this would not explain why phenomenological instructions alone were ineffective with standard and elimination lineups.

The question of which retrieval or post-retrieval mechanisms contributed to the effectiveness of the recollection lineup effect has implications for implementing phenomenological instructions in practice. Phenomenological instructions would allow eyewitnesses to better evaluate familiarity and recollection if 1) either lineup procedure or instructions cued recollection and/or 2) instructions improved memory monitoring so that both the presence and absence of recollection were considered (Guerin et al., 2012). If the effectiveness of instructions did not rely only on substantial recollection but on monitoring retrieved recollections (or their absence) and weighing them against familiarity, recollection 
lineups could potentially provide more reliable identification responses even when memory is poorer and recollection is less available. However, when phenomenological instructions were provided in elimination and standard simultaneous lineups that worked against effortful recollection, performance was not improved. Therefore, sufficient recollection or effort to recollect might be needed if instructions are to improve monitoring, and a lack of recollected detail might not be appropriately weighted. If so, phenomenological instructions might not be useful under poor encoding or retention conditions that limit the amount of detail that can be recollected. Illuminating the circumstances under which metacognitive interventions produce the biggest benefit is an important focus for future investigation.

\section{The recollection lineup}

The recollection lineup is promising but further testing is needed. The present studies represent a starting point for the development of procedural modifications that capitalise on witnesses' cognitive capacities to increase reliability. However, in the real world, witness preconceptions and expectations, including the pressure to make a positive identification, are likely to be stronger than those held by participants in the laboratory (e.g., Eisen, Smith, Olaguez, \& Skerritt-Perta, 2017). Therefore, rigorous testing in more realistic identification paradigms is a crucial next step. Similarly, the effects of extraneous cues that might encourage familiarity-based decision-making (e.g., administrator or co-witness bias) must be examined with any novel procedure. A procedure that relies on metacognitive influence for its efficacy will not be valuable if other known influences on metacognition are not controlled.

\section{Implications for recognition and lineup theory}

Our results have important implications for theories of eyewitness identification tasks and task design, supporting the idea that standard simultaneous lineups are associated with 
neglect of recollection, and adding to evidence that metacognitive interventions can improve memory use in identification decision-making. While the recollection lineup itself has potential applications, other interventions based on relevant lineup theory (e.g., Wixted et al., 2018) should be considered. Overall, our results reaffirm the value of extending basic memory theory directly to lineup tasks.

We also extended research on metacognitive instructions by demonstrating that providing more accurate information about a task is not always better than providing no task information. Blank and Launay (2014) surmised that the effectiveness of task-related instructions increased with specificity. However, we found that greater specificity affected response bias but did not improve discriminability. In lineups, detailed task awareness appeared to negate the benefits of a global phenomenological guide to memory accuracy that was effective when provided alone.

\section{Limitations}

To maximise statistical power and generalisability across a range of stimuli, we used a multiple lineup paradigm. Though this approach had distinct advantages, it also had limitations. Most significantly, the identification task differed in several important ways from the task of a real witness, including controlled and optimal encoding conditions, a brief retention interval, multiple trials, and no real-world consequences of lineup decisions. These factors could influence the effectiveness of the recollection lineup, and so it must be tested under more realistic conditions. Another significant limitation was that the offender-presence and best-match decisions were blocked, rather than interleaved, to avoid the possibility that participants would use a familiarity-based strategy for the best-match judgment in a lineup trial and then continue to use it for the offender-presence judgment in the following lineup trial, thus negating the effect of the delayed-choice procedure. Therefore, it will be important 
to test whether the recollection lineup would be as effective if the best-match selection immediately followed the offender-presence decision.

\section{Conclusions}

Our results were consistent with dual-process accounts of simultaneous lineup decision-making. The recollection lineup increased discriminability by reducing false identification, diverting participants from relying on familiarity and enhancing metacognitive awareness of how memory quality can be used to diagnose memory accuracy. The effectiveness of the recollection lineup showed basic recognition memory theory can underpin improvements in identification procedures. We also demonstrated that providing accurate task information could nevertheless trigger error-prone decision-making processes, and the effectiveness of phenomenological instructions depended on how they interacted with participants' metacognitive beliefs and the task's decision architecture. Overall, we demonstrated that neither delayed-choice nor phenomenological instructions independently improved discriminability in simultaneously-presented lineups, but that they were effective in combination. Hence, if metacognitive interventions are to increase the reliability of eyewitness identification decisions, decision structure and instructions must work in concert. 


\section{References}

Alban, M. W., \& Kelley, C. M. (2012). Variations in constrained retrieval. Memory \& Cognition, 40, 681-692. doi: 10.3758/s13421-012-0185-5

Bates, D. M., Maechler, M., Bolker, B., \& Walker, S. (2014)._lme4: Linear mixed-effects models using Eigen and S4_. Retrieved from http://CRAN.R-project.org/package=lme4

Blank, H., \& Launay, C. (2014). How to protect eyewitness memory against the misinformation effect: A meta-analysis of post-warning studies. Journal of Applied Research in Memory and Cognition, 3, 77-88. doi: 10.1016/j.jarmac.2014.03.005

Charman, S. D., Wells, G. L., \& Joy, S. W. (2011). The dud effect: Adding highly dissimilar fillers increases confidence in lineup identifications. Law and Human Behavior, 35, 479-500. doi: 10.1007/s10979-010-9261-1

Clark, S. E. (2003). A memory and decision model for eyewitness identification. Applied Cognitive Psychology, 17, 629-654. doi: 10.1002/acp.891

Clark, S. E. (2005). A re-examination of the effects of biased lineup instructions in eyewitness identification. Law and Human Behavior, 29, 575-604. doi: $10.1007 / \mathrm{s} 10979-005-7121-1$

Cook, G. I., Marsh, R. L., \& Hicks, J. L. (2005). Revisiting the role of recollection in item versus forced-choice recognition memory. Psychonomic Bulletin \& Review, 12, 720 725. doi: $10.3758 / \mathrm{bf} 03196763$

Eisen, M., L., Smith, A. M., Olaguez, A., \& Skerritt-Perta, A. S. (2017). An examination of showups conducted by law enforcement using a field-simulation paradigm. Psychology, Public Policy, and Law, 33, 1-22. doi: 10.1037/law0000115 
Fitzgerald, R. J., Oriet, C., \& Price, H. L. (2015). Suspect filler similarity in eyewitness lineups: A literature review and a novel methodology. Law and Human Behavior, 39, 62. doi: $10.1037 / \mathrm{lhb} 0000095$

Gallo, D. A. (2004). Using recall to reduce false recognition: diagnostic and disqualifying monitoring. Journal of Experimental Psychology: Learning, Memory, and Cognition, 30, 120-128. doi: 10.1037/0278-7393.30.1.120

Gallo, D. A. (2010). False memories and fantastic beliefs: 15 years of the DRM illusion. Memory \& Cognition, 38, 833-848. doi: $\underline{10.3758 / \mathrm{mc} .38 .7 .833}$

Gallo, D. A., Roediger, H. L., \& McDermott, K. B. (2001). Associative false recognition occurs without strategic criterion shifts. Psychonomic Bulletin \& Review, 8, 579-586. doi: $\underline{10.3758 / \mathrm{bf03196194}}$

Goodsell, C. A., Gronlund, S. D., \& Carlson, C. A. (2010). Exploring the sequential lineup advantage using WITNESS. Law and Human Behavior, 34, 445-459. doi: $10.1007 / \mathrm{s} 10979-009-9215-7$

Guerin, S. A., Robbins, C. A., Gilmore, A. W., \& Schacter, D. L. (2012). Retrieval failure contributes to gist-based false recognition. Journal of Memory and Language, 66, 6878. doi: $\underline{10.1016 / \mathrm{j} . j \mathrm{ml} 1.2011 .07 .002}$

Higham, P. A., Blank, H., \& Luna, K. (2017). Effects of postwarning specificity on memory performance and confidence in the eyewitness misinformation paradigm. Journal of experimental psychology: applied, 23(4), 417. doi: 10.1037/xap0000140

Johnson, M. K., Hashtroudi, S., \& Lindsay, D. S. (1993). Source monitoring. Psychological Bulletin, 114, 3-28. doi: 10.1037//0033-2909.114.1.3 
Judd, C. M., Westfall, J., \& Kenny, D. A. (2012). Treating stimuli as a random factor in social psychology: A new and comprehensive solution to a pervasive but largely ignored problem. Journal of personality and social psychology, 103, 54. doi: $10.1037 / \mathrm{a} 0028347$

Kahnemann, D. (2011). Thinking, fast and slow. New York: Farrar, Straus, \& Giroux.

Lane, S. M., Roussel, C. C., Villa, D., \& Morita, S. K. (2007). Features and feedback: Enhancing metamnemonic knowledge at retrieval reduces source-monitoring errors. Journal of Experimental Psychology: Learning, Memory, and Cognition, 33, 1131-1142. doi: 10.1037/0278-7393.33.6.1131

Lane, S. M., Roussel, C. C., Starns, J. J., Villa, D., \& Alonzo, J. D. (2008). Providing information about diagnostic features at retrieval reduces false recognition. Memory, 16, 836-851. http://doi: 10.1080/0965821080233734

Malmberg, K. J., \& Xu, J. (2007). On the flexibility and the fallibility of associative memory. Memory \& Cognition, 35, 545-556. doi: 10.3758/bf03193293

Mansour, J. K., Beaudry, J. L., \& Lindsay, R. C. L. (2017). Are multiple-trial experiments appropriate for eyewitness identification studies? Accuracy, choosing, and confidence across trials. Behavior research methods, 49(6), 2235-2254. doi: 10.3758/s13428-0170855-0

Mather, M., Henkel, L. A., \& Johnson, M. K. (1997). Evaluating characteristics of false memories: Remember/know judgments and memory characteristics questionnaire compared. Memory \& Cognition, 25(6), 826-837. doi: 10.3758/bf03211327

Mickes, Laura, et al. "ROC s in Eyewitness Identification: Instructions versus Confidence Ratings." Applied Cognitive Psychology 31.5 (2017): 467-477. 
Palmer, M. A., Brewer, N., McKinnon, A. C., \& Weber, N. (2010). Phenomenological reports diagnose accuracy of eyewitness identification decisions. Acta Psychologica, 133, 137-145. doi: 10.1016/j.actpsy.2009.11.002

Pozzulo, J. D., \& Lindsay, R. C. L. (1999). Elimination lineups: An improved identification procedure for child eyewitnesses. Journal of Applied Psychology, 84, 167. doi: $10.1037 / / 0021-9010.84 .2 .167$

R Core Team. (2014). R: A language and environment for statistical computing. Vienna: R Foundation for Statistical Computing. Retrieved from http://www.R-project.org.

Rotello, C. M., \& Heit, E. (2000). Associative recognition: A case of recall-to-reject processing. Memory \& Cognition, 28, 907-922. doi: 10.3758/BF03209339

Schooler, J. W., Gerhard, D., \& Loftus, E. F. (1986). Qualities of the unreal. Journal of Experimental Psychology: Learning, Memory, and Cognition, 12, 171-181. doi: $\underline{10.1037 / 0278-7393.12 .2 .171}$

Starns, J. J., Lane, S. M., Alonzo, J. D., \& Roussel, C. C. (2007). Metamnemonic control over the discriminability of memory evidence: A signal detection analysis of warning effects in the associative list paradigm. Journal of Memory and Language, 56, 592-607. doi: 10.1016/j.jml.2006.08.013

Wells, G. L. (1984). The Psychology of Lineup Identifications. Journal of Applied Social Psychology, 14, 89-103. doi: 10.1111/j.1559-1816.1984.tb02223.x

Wixted, J. T., \& Mickes, L. (2010). A continuous dual-process model of remember/know judgments. Psychological Review, 117, 1025-1054. doi: 10.1037/a0020874 
Wixted, J. T., \& Mickes, L. (2014). A signal-detection-based diagnostic-feature-detection model of eyewitness identification. Psychological Review, 121, 262-276. doi: $\underline{10.1037 / \mathrm{a} 0035940}$

Wixted, J. T., Mickes, L., Dunn, J. C., Clark, S. E., \& Wells, W. (2016). Estimating the reliability of eyewitness identifications from police lineups. Proceedings of the National Academy of Sciences, 113(2), 304-309.

Wixted, J. T., Vul, E., Mickes, L., \& Wilson, B. M. (2018a). Models of lineup memory. Cognitive psychology, 105, 81-114.

Wright, D.B., \& London, K. (2009). Multilevel modelling: Beyond the basic applications. British Journal of Mathematical and Statistical Psychology, 62, 439-456. doi: $\underline{10.1348 / 000711008 \times 327632}$ 


\section{METACOGNITIVE CONTROL AND LINEUP INSTRUCTIONS}

Table 1

Descriptive Statistics* for Lineup Responses (Accurate Identification (ID) rates (Hit rates), Filler ID Rates, Correct Rejection Rates, False ID

Rates, Overall Accuracy) and Aggregate Signal Detection Measures (d', c) by Lineup Type, Experiment 1

\begin{tabular}{|c|c|c|c|c|c|c|c|c|c|c|c|c|c|}
\hline & \multicolumn{10}{|c|}{ Response Proportion } & \multirow{2}{*}{\multicolumn{2}{|c|}{$\begin{array}{c}\text { Signal Detection } \\
\text { Measures }\end{array}$}} & \multirow{2}{*}{$\begin{array}{c}\text { Lineup } \\
\text { Comparison } \\
\text { (vs S) }\end{array}$} \\
\hline & & \multicolumn{4}{|c|}{ Target-present } & \multicolumn{3}{|c|}{ Target-absent } & \multicolumn{2}{|r|}{$\begin{array}{c}\text { All } \\
\text { Trials }\end{array}$} & & & \\
\hline Lineup & Statistic & Hits & Filler & Incorrect & $n$ & Correct & Filler & False & $n$ & Overall & $d^{\prime}$ & $C$ & Cohen's $d$ \\
\hline type & & & IDs & Rejections & & Rejections & IDs & IDs & & accuracy & & & for $d^{\prime}$ \\
\hline \multirow[t]{3}{*}{$\mathrm{S}$} & $M$ & .65 & .12 & .23 & 30 & .64 & .24 & .13 & 30 & 0.65 & 1.51 & 0.37 & - \\
\hline & $S D$ & .16 & .11 & .14 & & .24 & .16 & .11 & & 0.20 & 0.81 & 0.14 & - \\
\hline & $95 \% \mathrm{CI}$ & $.64, .66$ & $.11, .13$ & $.22, .24$ & & $.62, .65$ & $.22, .25$ & $.12, .14$ & & $.64, .66$ & $1.45,1.57$ & $0.36,0.38$ & - \\
\hline \multirow[t]{3}{*}{$\mathrm{DC}$} & $M$ & .50 & .18 & .32 & 30 & .69 & .19 & .12 & 30 & 0.60 & 1.12 & 0.59 & 0.48 \\
\hline & $S D$ & .19 & .13 & .13 & & .20 & .15 & .09 & & 0.20 & 0.81 & 0.11 & - \\
\hline & $95 \% \mathrm{CI}$ & $.48, .52$ & $.17, .19$ & $.31, .33$ & & $.67, .70$ & $.18, .21$ & $.11, .13$ & & $.59, .61$ & $1.06,1.18$ & $0.58,0.60$ & - \\
\hline
\end{tabular}




$\begin{array}{cccccccccccccccc}\text { DCI } & M & .57 & .10 & .33 & 33 & .79 & .13 & .08 & 33 & 0.68 & 1.58 & 0.61 & 0.09 \\ & S D & .19 & .11 & .17 & & .16 & .14 & .07 & & 0.18 & 0.79 & 0.11 \\ & 95 \% \text { CI } & .56, .59 & .09, .11 & .31, .34 & & .78, .80 & .12, .14 & .08, .09 & & .67, .69 & 1.52,1.64 & 0.60,0.62 & -\end{array}$

* Note: Inferential analysis of aggregate data give biased estimates of effects when both participant and stimuli are random factors (Judd,

Westfall, \& Kenny, 2012). Refer to mixed effects models for tests of experimental factors. $\mathrm{S}=$ Standard simultaneous lineup; DC = Delayedchoice lineup; DCI = Delayed-choice lineup with instructions; 
Table 2

Models Predicting Identification Decisions by Lineup Type Comparison and Outcome Measure, Experiment 1

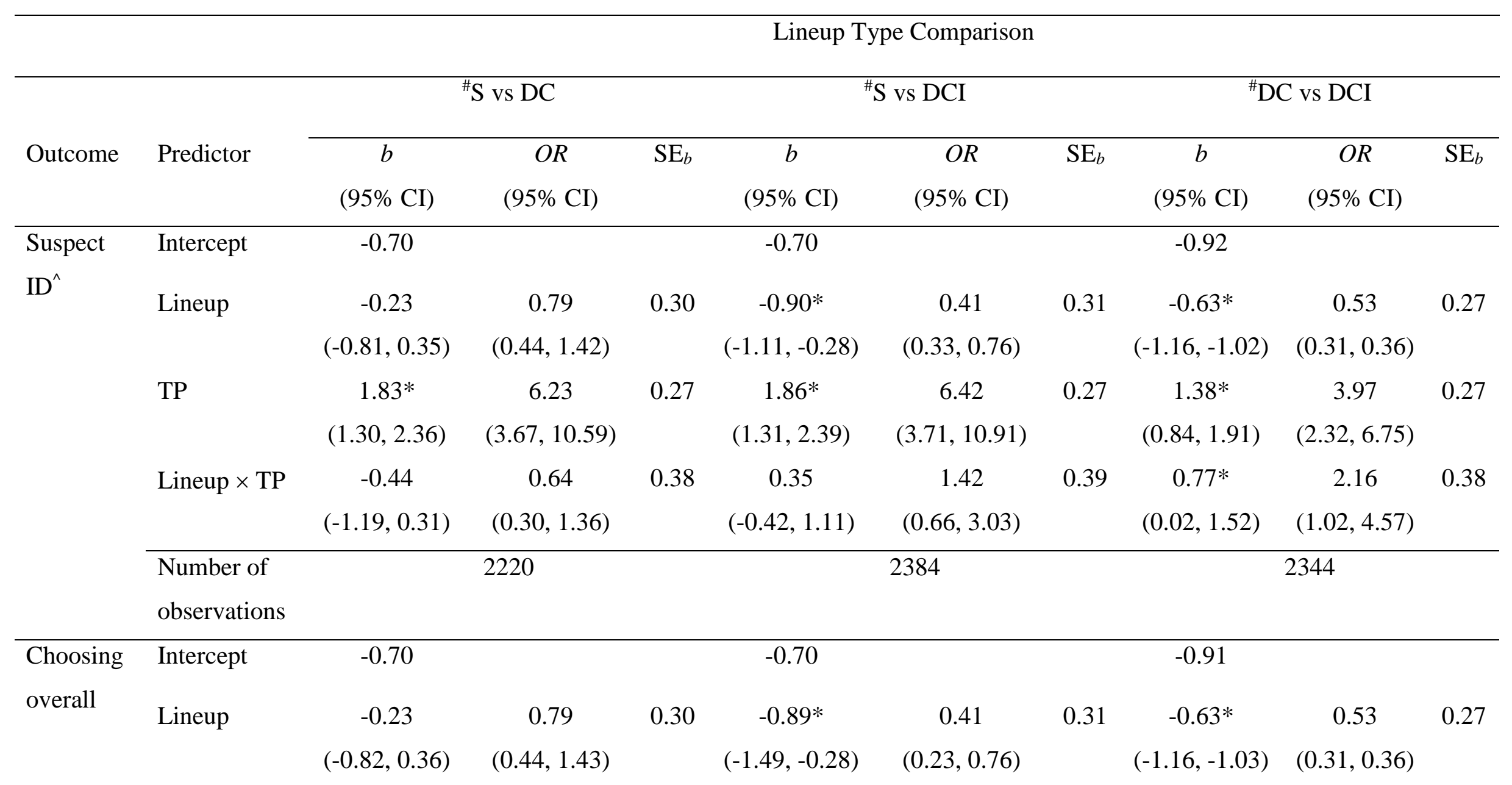




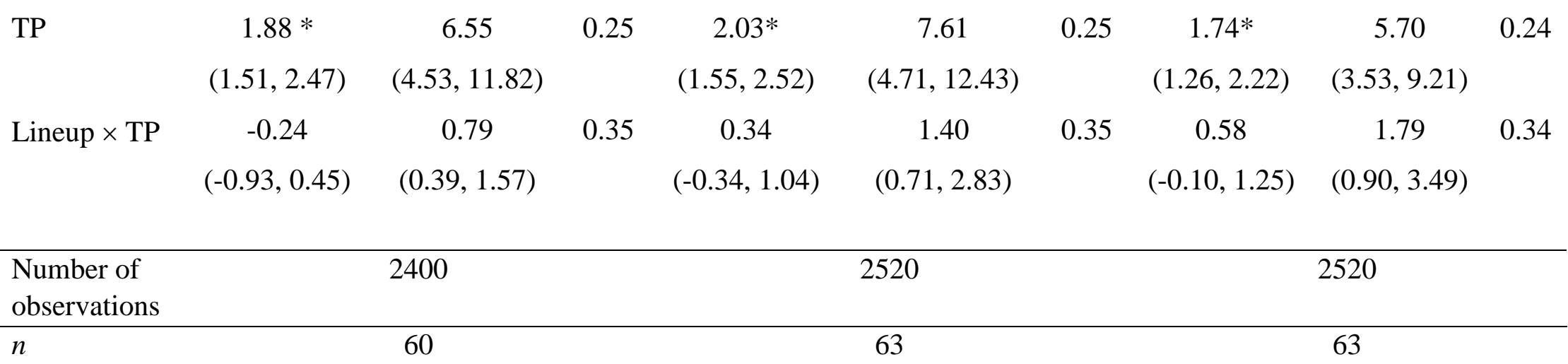

Note: $\mathrm{S}=$ Standard simultaneous lineup; DC = Delayed-choice lineup; DCI = Delayed-choice lineup with instructions; ${ }^{\#}$ indicates the reference lineup condition; * indicates significant predictors; ${ }^{\wedge}$ filler selections excluded. 
Table 3

Descriptive Statistics* for Lineup Responses (Accurate Identification (ID) rates (Hit rates), Filler ID Rates, Correct Rejection Rates, False ID

Rates, Overall Accuracy) and Aggregate Signal Detection Measures (d', c) by Lineup Type, Experiment 2

\begin{tabular}{|c|c|c|c|c|c|c|c|c|c|c|c|c|c|}
\hline & \multicolumn{10}{|c|}{ Response Proportion } & \multirow{2}{*}{\multicolumn{2}{|c|}{$\begin{array}{c}\text { Signal Detection } \\
\text { Measures }\end{array}$}} & \multirow{2}{*}{$\begin{array}{c}\text { Lineup } \\
\text { Comparison } \\
\text { (vs S) }\end{array}$} \\
\hline & & \multicolumn{4}{|c|}{ Target-present } & \multicolumn{3}{|c|}{ Target-absent } & \multicolumn{2}{|r|}{$\begin{array}{c}\text { All } \\
\text { Trials }\end{array}$} & & & \\
\hline Lineup & Statistic & Hits & Filler & Incorrect & $n$ & Correct & Filler & False & $n$ & Overall & $d^{\prime}$ & $C$ & Cohen's $d$ \\
\hline type & & & IDs & Rejections & & Rejections & IDs & IDs & & accuracy & & & for $d^{\prime}$ \\
\hline \multirow[t]{3}{*}{$S$} & $M$ & .51 & .15 & .34 & 32 & .63 & .26 & .11 & 32 & 0.57 & 1.25 & 0.31 & - \\
\hline & $S D$ & .19 & .10 & .18 & & .21 & .17 & .09 & & 0.20 & 0.54 & 0.11 & - \\
\hline & $95 \% \mathrm{CI}$ & $.50, .53$ & $.14, .16$ & $.32, .35$ & & $.61, .65$ & $.24, .27$ & $.10, .12$ & & $.56, .58$ & $1.21,1.29$ & $0.30,0.32$ & - \\
\hline \multirow[t]{3}{*}{ SI } & $M$ & .43 & .13 & .44 & 32 & .70 & .24 & .06 & 32 & 0.57 & 1.40 & 0.24 & 0.30 \\
\hline & $S D$ & .21 & .09 & .24 & & .25 & .22 & .06 & & 0.17 & 0.47 & 0.11 & - \\
\hline & $95 \% \mathrm{CI}$ & $.41, .45$ & $.12, .14$ & $.42, .46$ & & $.68, .72$ & $.22, .26$ & $.05, .06$ & & $.56, .58$ & $1.36,1.44$ & $0.23,0.25$ & - \\
\hline
\end{tabular}




\begin{tabular}{|c|c|c|c|c|c|c|c|c|c|c|c|c|c|}
\hline \multirow[t]{3}{*}{$\mathrm{DC}$} & $M$ & .47 & .13 & .40 & 32 & .71 & .21 & .08 & 32 & 0.59 & 1.34 & 0.28 & 0.10 \\
\hline & $S D$ & .15 & .09 & .16 & & .15 & .13 & .07 & & 0.15 & 0.55 & 0.08 & - \\
\hline & $95 \% \mathrm{CI}$ & $.46, .48$ & $.12, .13$ & $.39, .41$ & & $.70, .73$ & $.20, .22$ & $.07, .08$ & & $.58, .60$ & $1.30,1.38$ & $0.27,0.29$ & - \\
\hline \multirow[t]{3}{*}{ DCI } & $M$ & .45 & .10 & .45 & 32 & .79 & .16 & .05 & 32 & 0.62 & 1.49 & 0.25 & 0.48 \\
\hline & $S D$ & .19 & .11 & .21 & & .17 & .14 & .05 & & 0.18 & 0.45 & 0.10 & - \\
\hline & $95 \% \mathrm{CI}$ & $.43, .46$ & $.09, .11$ & $.44, .47$ & & $.77, .80$ & $.15, .17$ & $.05, .06$ & & $.61, .63$ & $1.46,1.52$ & $0.24,0.26$ & - \\
\hline
\end{tabular}

\footnotetext{
* Note: Inferential analysis of aggregate data give biased estimates of effects when both participant and stimuli are random factors (Judd,

Westfall, \& Kenny, 2012). Refer to mixed effects models for tests of experimental factors. S = Standard simultaneous lineup; SI = Standard simultaneous lineup with instructions; DC = Delayed-choice lineup; DCI = Delayed-choice lineup with instructions
} 
Table 4

Models predicting Identification Decisions by Lineup Type Comparison and Outcome Measure, Experiment 2

\begin{tabular}{|c|c|c|c|c|c|c|c|}
\hline \multirow[b]{3}{*}{ Outcome } & \multirow[b]{3}{*}{ Predictor } & \multicolumn{6}{|c|}{ Lineup Type Comparison } \\
\hline & & \multicolumn{3}{|c|}{${ }^{\#} \mathrm{~S}$ vs DC } & \multicolumn{3}{|c|}{${ }^{\#} \mathrm{~S}$ vs DCI } \\
\hline & & $\begin{array}{c}b \\
(95 \% \mathrm{CI})\end{array}$ & $\begin{array}{c}\text { OR } \\
(95 \% \mathrm{CI})\end{array}$ & $\mathrm{SE}_{b}$ & $\begin{array}{c}b \\
(95 \% \mathrm{CI})\end{array}$ & $\begin{array}{c}\text { OR } \\
(95 \% \mathrm{CI})\end{array}$ & $\mathrm{SE}_{b}$ \\
\hline \multirow[t]{5}{*}{ Suspect ID $^{\wedge}$} & Intercept & -2.18 & & & -2.16 & & \\
\hline & Lineup & $\begin{array}{c}-0.55 \\
(-1.16,0.06)\end{array}$ & $\begin{array}{c}0.58 \\
(0.32,1.05)\end{array}$ & 0.31 & $\begin{array}{c}-0.89 * \\
(-1.54,-0.24)\end{array}$ & $\begin{array}{c}0.41 \\
(0.21,0.79)\end{array}$ & 0.33 \\
\hline & $\mathrm{TP}$ & $\begin{array}{c}2.63^{*} \\
(2.18,3.08)\end{array}$ & $\begin{array}{c}13.87 \\
(8.85,21.76)\end{array}$ & 0.23 & $\begin{array}{c}2.65^{*} \\
(2.22,3.08)\end{array}$ & $\begin{array}{c}14.15 \\
(9.12,21.98)\end{array}$ & 0.22 \\
\hline & Lineup $\times \mathrm{TP}$ & $\begin{array}{c}0.26 \\
(-0.33,0.85)\end{array}$ & $\begin{array}{c}1.30 \\
(0.73,2.34)\end{array}$ & 0.30 & $\begin{array}{c}0.37 \\
(-0.24,0.98)\end{array}$ & $\begin{array}{c}1.45 \\
(0.79,2.66)\end{array}$ & 0.31 \\
\hline & Number of observations & & 2086 & & & 2131 & \\
\hline \multirow[t]{3}{*}{ Choosing overall } & Intercept & -0.62 & & & -0.64 & & \\
\hline & Lineup & $\begin{array}{c}-0.41 \\
(-0.86,0.04)\end{array}$ & $\begin{array}{c}0.66 \\
(0.42,1.04)\end{array}$ & 0.23 & $\begin{array}{c}-0.93 * \\
(-1.46,-0.40)\end{array}$ & $\begin{array}{c}0.39 \\
(0.23,0.67)\end{array}$ & 0.27 \\
\hline & $\mathrm{TP}$ & $\begin{array}{c}1.36^{*} \\
(1.03,1.69)\end{array}$ & $\begin{array}{c}3.90 \\
(2.77,5.42)\end{array}$ & 0.17 & $\begin{array}{c}1.41^{*} \\
(1.04,1.78)\end{array}$ & $\begin{array}{c}4.10 \\
(2.83,5.93)\end{array}$ & 0.19 \\
\hline
\end{tabular}




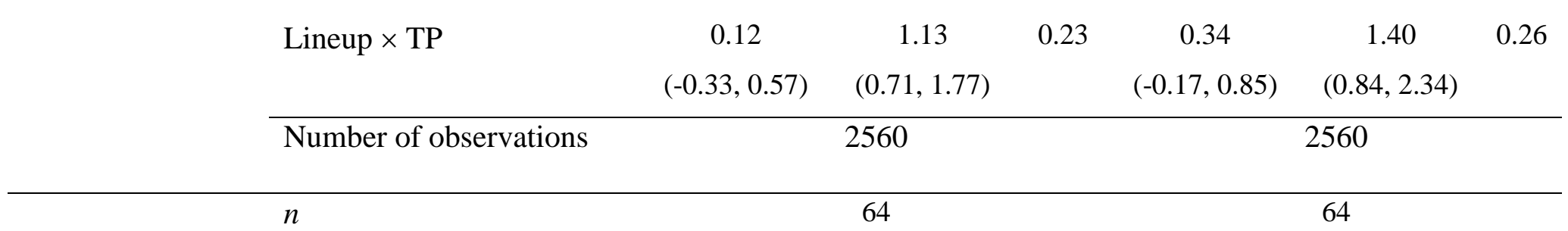

\begin{tabular}{|c|c|c|c|c|c|c|c|}
\hline \multirow[b]{2}{*}{ Outcome } & \multirow[b]{2}{*}{ Predictor } & \multicolumn{3}{|c|}{${ }^{\#} \mathrm{~S}$ vs SI } & \multicolumn{3}{|c|}{${ }^{\#} \mathrm{DC}$ vs DCI } \\
\hline & & $\begin{array}{c}b \\
(95 \% \mathrm{CI})\end{array}$ & $\begin{array}{c}\text { OR } \\
(95 \% \mathrm{CI})\end{array}$ & $\mathrm{SE}_{b}$ & $\begin{array}{c}b \\
(95 \% \mathrm{CI})\end{array}$ & $\begin{array}{c}\text { OR } \\
(95 \% \mathrm{CI})\end{array}$ & $\mathrm{SE}_{b}$ \\
\hline \multirow[t]{5}{*}{ Suspect ID^ } & Intercept & -2.07 & & & -2.61 & & \\
\hline & Lineup & $\begin{array}{c}-0.90 * \\
(-1.39,0.41)\end{array}$ & $\begin{array}{c}0.41 \\
(0.25,1.49)\end{array}$ & 0.25 & $\begin{array}{c}-0.70^{*} \\
(-1.27,-0.13)\end{array}$ & $\begin{array}{c}0.50 \\
(0.28,0.87)\end{array}$ & 0.29 \\
\hline & $\mathrm{TP}$ & $\begin{array}{c}2.54 * \\
(2.09,2.99)\end{array}$ & $\begin{array}{c}12.68 \\
(8.08,19.89)\end{array}$ & 0.23 & $\begin{array}{c}2.74 * \\
(2.29,3.19)\end{array}$ & $\begin{array}{c}15.49 \\
(9.87,24.29)\end{array}$ & 0.23 \\
\hline & Lineup $\times \mathrm{TP}$ & $\begin{array}{c}-0.78^{*} \\
(-1.37,-0.19)\end{array}$ & $\begin{array}{c}0.46 \\
(0.25,0.83)\end{array}$ & -.30 & $\begin{array}{c}0.49 \\
(-0.08,1.06)\end{array}$ & $\begin{array}{c}1.63 \\
(0.92,2.89)\end{array}$ & 0.29 \\
\hline & Number of observations & & 1870 & & & 2179 & \\
\hline \multirow[t]{2}{*}{ Choosing overall } & Intercept & -0.67 & & & -1.04 & & \\
\hline & Lineup & $\begin{array}{c}-0.59 * \\
(-1.00,-0.18)\end{array}$ & $\begin{array}{c}0.55 \\
(0.37,0.83)\end{array}$ & 0.21 & $\begin{array}{c}-0.54 * \\
(-0.85,-0.23)\end{array}$ & $\begin{array}{c}0.58 \\
(0.43,0.79)\end{array}$ & 0.16 \\
\hline
\end{tabular}




\begin{tabular}{lcccccc} 
TP & $1.41^{*}$ & 4.10 & 0.20 & $1.46^{*}$ & 4.31 & 0.17 \\
& $(1.02,1.80)$ & $(2.77,6.05)$ & & $(1.13,1.79)$ & $(3.10,5.99)$ & \\
Lineup $\times$ TP & -0.11 & 0.90 & 0.23 & 0.29 & 1.34 & 0.19 \\
& $(-0.56,0.34)$ & $(0.57,1.40)$ & & $(-0.08,0.66)$ & $(0.92,1.92)$ \\
\cline { 2 - 6 } & \multicolumn{2}{c}{2560} & & \multicolumn{2}{c}{25600} \\
\hline
\end{tabular}

Note: $\mathrm{S}$ = Standard simultaneous lineup; SI = Standard simultaneous lineup with instructions; DC = Delayed-choice simultaneous lineup; DCI =

Delayed-choice simultaneous lineup with instructions; ${ }^{\#}$ indicates the reference lineup condition; $*$ indicates significant predictors; ${ }^{\wedge}$ filler selections excluded. 
Table 5

Descriptive Statistics* for Lineup Responses (Accurate Identification (ID) rates (Hit rates), Filler ID Rates, Correct Rejection Rates, False ID

Rates, Overall Accuracy) and Aggregate Signal Detection Measures (d', c) by Lineup Type, Experiment 3

\begin{tabular}{|c|c|c|c|c|c|c|c|c|c|c|c|c|c|}
\hline & \multicolumn{10}{|c|}{ Response Proportion } & \multirow{2}{*}{\multicolumn{2}{|c|}{$\begin{array}{c}\text { Signal Detection } \\
\text { Measures }\end{array}$}} & \multirow{2}{*}{$\begin{array}{c}\text { Lineup } \\
\text { Comparison } \\
\text { (vs S) }\end{array}$} \\
\hline & & \multicolumn{4}{|c|}{ Target-present } & \multicolumn{3}{|c|}{ Target-absent } & \multicolumn{2}{|r|}{$\begin{array}{c}\text { All } \\
\text { Trials }\end{array}$} & & & \\
\hline Lineup & Statistic & Hits & Filler & Incorrect & $n$ & Correct & Filler & False & $n$ & Overall & $d^{\prime}$ & $C$ & Cohen's $d$ \\
\hline Type & & & IDs & Rejections & & Rejections & IDs & IDs & & accuracy & & & for $d^{\prime}$ \\
\hline \multirow[t]{3}{*}{ S } & $M$ & .49 & .18 & .32 & 32 & .59 & .30 & .12 & 32 & 0.54 & 1.24 & 0.31 & - \\
\hline & $S D$ & .15 & .12 & .16 & & .17 & .14 & .07 & & 0.16 & 0.51 & 0.09 & - \\
\hline & $95 \% \mathrm{CI}$ & $.48, .50$ & $.18, .19$ & $.32, .33$ & & $.58, .59$ & $.29, .33$ & $.12, .12$ & & $.53, .55$ & $1.21,1.27$ & $0.31,0.31$ & - \\
\hline \multirow[t]{2}{*}{ DCI } & $M$ & .50 & .12 & .37 & 32 & .72 & .19 & .09 & 32 & 0.61 & 1.42 & 0.32 & 0.19 \\
\hline & $S D$ & .14 & .09 & .14 & & .16 & .11 & .06 & & 0.15 & 0.48 & 0.08 & - \\
\hline
\end{tabular}




\begin{tabular}{|c|c|c|c|c|c|c|c|c|c|c|c|c|}
\hline $95 \% \mathrm{CI}$ & $.50, .51$ & $.12, .13$ & $.37, .38$ & & $.71, .73$ & $.18, .19$ & $.09, .09$ & & $.60, .62$ & $1.39,1.45$ & $0.32,0.32$ & - \\
\hline$M$ & .52 & .17 & .31 & 32 & .58 & .29 & .12 & 32 & 0.55 & 1.29 & 0.30 & 0.10 \\
\hline$S D$ & .13 & .14 & .11 & & .17 & .14 & .08 & & 0.15 & 0.53 & 0.07 & - \\
\hline $95 \% \mathrm{CI}$ & $.51, .53$ & $.16, .18$ & $.31, .32$ & & $.58, .59$ & $.29, .33$ & $.12, .13$ & & $.54, .56$ & $1.26,1.32$ & $0.30,0.30$ & - \\
\hline
\end{tabular}

* Note: Inferential analysis of aggregate data give biased estimates of effects when both participant and stimuli are random factors (Judd,

Westfall, \& Kenny, 2012). Refer to mixed effects models for tests of experimental factors. S = Standard simultaneous lineup; SI = Standard simultaneous lineup with instructions; DCI = Delayed-choice lineup with instructions 
Table 6

Models Predicting Identification Decisions by Lineup Type Comparison and Outcome

Measure, Experiment 3

\section{Lineup Type Comparison}

\begin{tabular}{|c|c|c|c|c|c|c|c|}
\hline \multirow[b]{2}{*}{ Outcome } & \multirow[b]{2}{*}{ Predictor } & \multicolumn{3}{|c|}{${ }^{\#} \mathrm{~S}$ vs DCI } & \multicolumn{3}{|c|}{${ }^{\#} \mathrm{~S}$ vs SI } \\
\hline & & $\begin{array}{c}b \\
(95 \% \mathrm{CI})\end{array}$ & $\begin{array}{c}\text { OR } \\
(95 \% \mathrm{CI})\end{array}$ & $\mathrm{SE}_{b}$ & $\begin{array}{c}b \\
(95 \% \mathrm{CI})\end{array}$ & $\begin{array}{c}O R \\
(95 \% \mathrm{CI})\end{array}$ & $\mathrm{SE}_{b}$ \\
\hline \multirow{5}{*}{$\begin{array}{l}\text { Suspect } \\
\text { ID }^{\wedge}\end{array}$} & Intercept & -0.40 & & & -0.39 & & \\
\hline & Lineup & $\begin{array}{c}*_{-} 0.71 \\
(-1.11,-0.30)\end{array}$ & $\begin{array}{c}0.49 \\
(.033,0.74)\end{array}$ & 0.21 & $\begin{array}{c}0.00 \\
(-0.39,0.39)\end{array}$ & $\begin{array}{c}1.00 \\
(0.68,1.48)\end{array}$ & 0.20 \\
\hline & $\mathrm{TP}$ & $\begin{array}{c}* 0.83 \\
(0.47,1.18)\end{array}$ & $\begin{array}{c}2.29 \\
(1.60,3.25)\end{array}$ & 0.18 & $\begin{array}{c}* 0.83 \\
(0.52,1.14)\end{array}$ & $\begin{array}{c}2.29 \\
(1.68,3.13)\end{array}$ & 0.16 \\
\hline & Lineup $\times \mathrm{TP}$ & $\begin{array}{c}* 0.53 \\
(0.08,0.98)\end{array}$ & $\begin{array}{c}1.70 \\
(1.08,2.66)\end{array}$ & 0.23 & $\begin{array}{c}0.06 \\
(-0.34,0.48)\end{array}$ & $\begin{array}{c}1.06 \\
(0.71,1.62)\end{array}$ & 0.21 \\
\hline & $\begin{array}{l}\text { Number of } \\
\text { observations }\end{array}$ & & 4727 & & & 4669 & \\
\hline \multirow{6}{*}{$\begin{array}{l}\text { Choosing } \\
\text { overall }\end{array}$} & Intercept & -0.40 & & & -0.40 & & \\
\hline & Lineup & $\begin{array}{c}-0.71 * \\
(-1.11,-0.30)\end{array}$ & $\begin{array}{c}0.49 \\
(0.33,0.74)\end{array}$ & 0.21 & $\begin{array}{c}0.00 \\
(-0.39,0.39)\end{array}$ & $\begin{array}{c}1.00 \\
(0.68 .1 .48)\end{array}$ & 0.20 \\
\hline & $\mathrm{TP}$ & $\begin{array}{c}1.20 * \\
(0.89,1.50)\end{array}$ & $\begin{array}{c}3.32 \\
(2.44,4.48)\end{array}$ & 0.16 & $\begin{array}{c}1.19 * \\
(0.91,1.46)\end{array}$ & $\begin{array}{c}3.29 \\
(2.48 .4,31)\end{array}$ & 0.14 \\
\hline & Lineup $\times \mathrm{TP}$ & $\begin{array}{c}0.44 * \\
(0.06,0.83)\end{array}$ & $\begin{array}{c}1.55 \\
(1.06 .2 .29)\end{array}$ & 0.20 & $\begin{array}{c}0.04 \\
(-0.29,0.38)\end{array}$ & $\begin{array}{c}1.04 \\
(0.75,1.46)\end{array}$ & 0.17 \\
\hline & $\begin{array}{l}\text { Number of } \\
\text { observations }\end{array}$ & & 5120 & & & 5120 & \\
\hline & $n$ & & 64 & & & 64 & \\
\hline
\end{tabular}


Note: $\mathrm{S}=$ Standard simultaneous lineup; $\mathrm{SI}=$ Standard simultaneous lineup with instructions; DCI = Delayed-choice lineup with instructions; ${ }^{~}$ indicates the reference lineup condition; * indicates significant predictors; ${ }^{\wedge}$ filler selections excluded. 
Table 7

Descriptive Statistics* for Lineup Responses (Accurate Identification (ID) rates (Hit rates), Filler ID Rates, Correct Rejection Rates, False ID Rates, Overall Accuracy) and Aggregate Signal Detection Measures (d', c) by Lineup Type, Experiment 4

\section{Response Proportion}

Target-present
Target-absent

Tria

\begin{tabular}{|c|c|c|c|c|c|c|c|c|c|c|}
\hline Lineup & Statistic & Hits & Filler & Incorrect & $n$ & Correct & Filler & False & $n$ & Over \\
\hline type & & & IDs & Rejections & & Rejections & IDs & IDs & & acc \\
\hline \multirow[t]{3}{*}{$\mathrm{S}$} & $M$ & .43 & .16 & .40 & 45 & .73 & .20 & .07 & 45 & \\
\hline & $S D$ & .17 & .14 & .15 & & .20 & .16 & .07 & & 0 \\
\hline & $95 \% \mathrm{CI}$ & $.42, .44$ & $.15, .17$ & $.39, .41$ & & $.72, .75$ & $.19, .21$ & $.07, .08$ & & .57 \\
\hline \multirow[t]{3}{*}{$\mathrm{E}$} & $M$ & .39 & .13 & .48 & 33 & .71 & .21 & .07 & 33 & \\
\hline & $S D$ & .17 & .13 & .19 & & .20 & .15 & .07 & & \\
\hline & $95 \% \mathrm{CI}$ & $.38, .40$ & $.12, .14$ & $.46, .49$ & & $.70, .73$ & $.20, .22$ & $.07, .08$ & & .54 \\
\hline \multirow[t]{3}{*}{ EI } & $M$ & .40 & .14 & .46 & 34 & .70 & .23 & .08 & 34 & \\
\hline & $S D$ & .19 & .15 & .19 & & .20 & .17 & .08 & & \\
\hline & $95 \% \mathrm{CI}$ & $.39, .41$ & $.13, .15$ & $.45, .48$ & & $.68, .71$ & $.21, .24$ & $.07, .09$ & & .54 \\
\hline
\end{tabular}

* Note: Inferential analysis of aggregate data give biased estimates of effects when both participant and stimuli are random factors (Judd, Westfall, \& Kenny, 2012). Refer to mixed effects models for tests of experimental factors. $\mathrm{S}=$ Standard simultaneous lineup; $\mathrm{E}=$ Elimination lineup; EI = Elimination lineup with instructions 
Table 8

Models Predicting Identification Decisions by Lineup Comparison and Outcome Measure,

Experiment 4

Lineup Type Comparisons

\begin{tabular}{|c|c|c|c|c|c|c|c|c|c|c|}
\hline \multirow{4}{*}{$\begin{array}{l}\text { Outcom } \\
\mathrm{e}\end{array}$} & \multirow{4}{*}{$\begin{array}{l}\text { Predicto } \\
\mathrm{r}\end{array}$} & \multicolumn{3}{|c|}{${ }^{\#} \mathrm{~S}$ vs EI } & \multicolumn{3}{|c|}{${ }^{\#} \mathrm{E}$ vs EI } & \multicolumn{3}{|c|}{${ }^{\#} \mathrm{~S}$ vs $\mathrm{E}$} \\
\hline & & $b$ & $O R$ & $S$ & $b$ & $O R$ & $S$ & $b$ & $O R$ & $S$ \\
\hline & & $(95 \% \mathrm{CI}$ & $(95 \% \mathrm{CI}$ & $\mathrm{E}$ & $(95 \% \mathrm{C}$ & $(95 \% \mathrm{CI}$ & $\mathrm{E}_{b}$ & $(95 \% \mathrm{C}$ & $(95 \% \mathrm{CI}$ & $\mathrm{E}_{b}$ \\
\hline & & ) & ) & $b$ & I) & ) & & I) & ) & \\
\hline \multirow{15}{*}{$\begin{array}{l}\text { Suspect } \\
\mathrm{ID}^{\wedge}\end{array}$} & Intercep & -2.46 & & & -2.91 & & & -2.44 & & \\
\hline & $\mathrm{t}$ & & & & & & & & & \\
\hline & Lineup & 0.01 & 1.01 & 0. & 0.39 & 1.48 & 0. & -0.55 & 0.58 & 0. \\
\hline & & $(-0.64$ & $(0.53$ & 3 & $(-0.30$ & $(0.74$ & 35 & $(-1.29$, & $(0.28$, & 38 \\
\hline & & $0.65)$ & 1.92) & 3 & $1.07)$ & 2.92) & & 0.19) & 1.21) & \\
\hline & $\mathrm{TP}$ & $2.57 *$ & 13.07 & 0. & $2.72 *$ & 15.18 & 0. & $2.41 *$ & 11.13 & 0. \\
\hline & & (1.91, & $(6.75$ & 3 & $(2.14$, & $(8.50$ & 30 & (1.82, & $(6.17$. & 30 \\
\hline & & 3.22) & 25.03) & 4 & 3.30) & 27.11) & & $3.00)$ & 20.09) & \\
\hline & Lineup & -0.32 & 0.73 & 0. & -0.38 & 0.68 & 0. & 0.38 & 1.46 & 0. \\
\hline & $\times \mathrm{TP}$ & $(-1.19$ & $(0.30$ & 4 & $(-1.16$, & $(0.31$ & 39 & $(-0.44$, & $(0.64$ & 42 \\
\hline & & $0.54)$ & 1.72) & 4 & 0.39) & 1.48) & & $1.20)$ & 3.32) & \\
\hline & Number & & 1831 & & & 2204 & & & 1809 & \\
\hline & of & & & & & & & & & \\
\hline & observa & & & & & & & & & \\
\hline & tions & & & & & & & & & \\
\hline \multirow{8}{*}{$\begin{array}{l}\text { Choosin } \\
\text { g overall }\end{array}$} & Intercep & -1.10 & & & -1.13 & & & -1.08 & & \\
\hline & $\mathrm{t}$ & & & & & & & & & \\
\hline & Lineup & 0.10 & 1.11 & 0. & 0.14 & 1.15 & 0. & -0.05 & 0.95 & 0. \\
\hline & & $(-0.43$, & $(0.65$ & 2 & $(-0.41$, & $(0.66$ & 28 & $(-0.57$, & $(0.57$ & 27 \\
\hline & & $0.63)$ & 1.88) & 7 & 0.69) & 1.99) & & $0.46)$ & $1.58)$ & \\
\hline & $\mathrm{TP}$ & $1.64 *$ & 5.16 & 0. & $1.28 *$ & 3.60 & 0. & $1.55 *$ & 4.71 & 0. \\
\hline & & $(1.19$, & $(3.29$ & 2 & $(0.90$ & $(2.46$ & 20 & $(1.17$, & $(3.22$, & 19 \\
\hline & & 2.09) & 8.08) & 3 & 1.67) & 5.31) & & 1.92) & $6.82)$ & \\
\hline
\end{tabular}




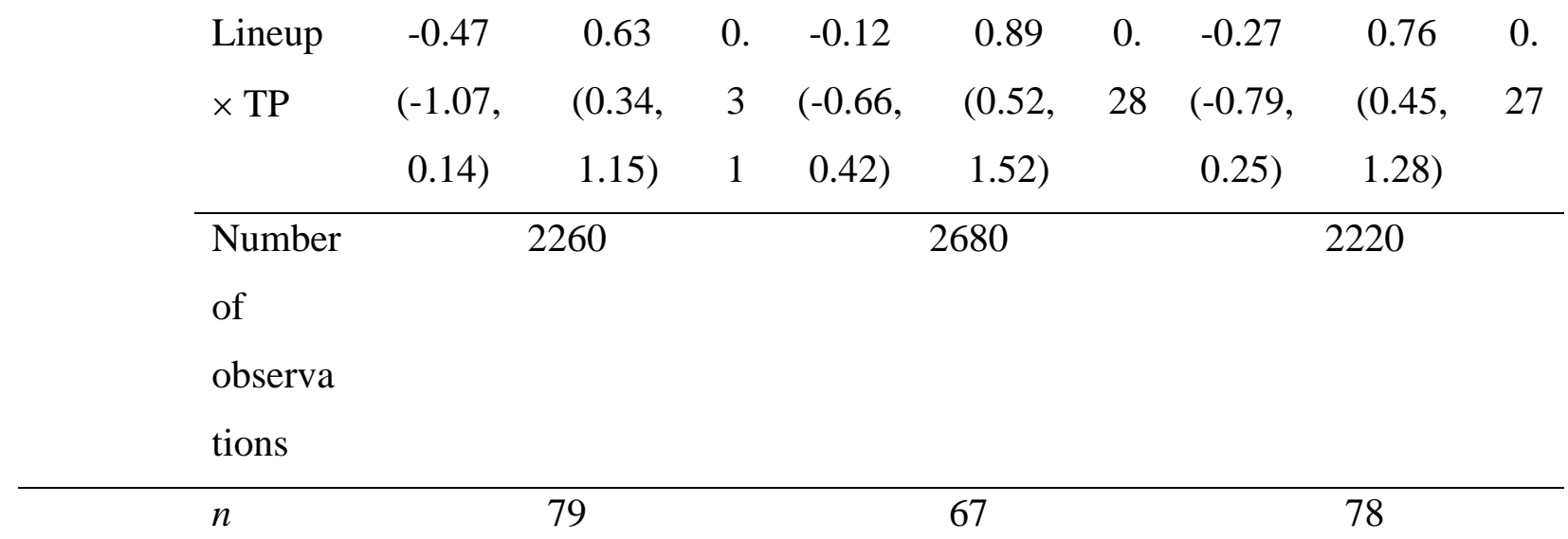

Note: $\mathrm{S}=$ Standard simultaneous lineup; Elimination = Elimination simultaneous lineups; EI

$=$ Elimination simultaneous lineup with instructions; ${ }^{*}$ indicates the reference lineup condition; * indicates significant predictors; ${ }^{\wedge}$ filler selections excluded. 


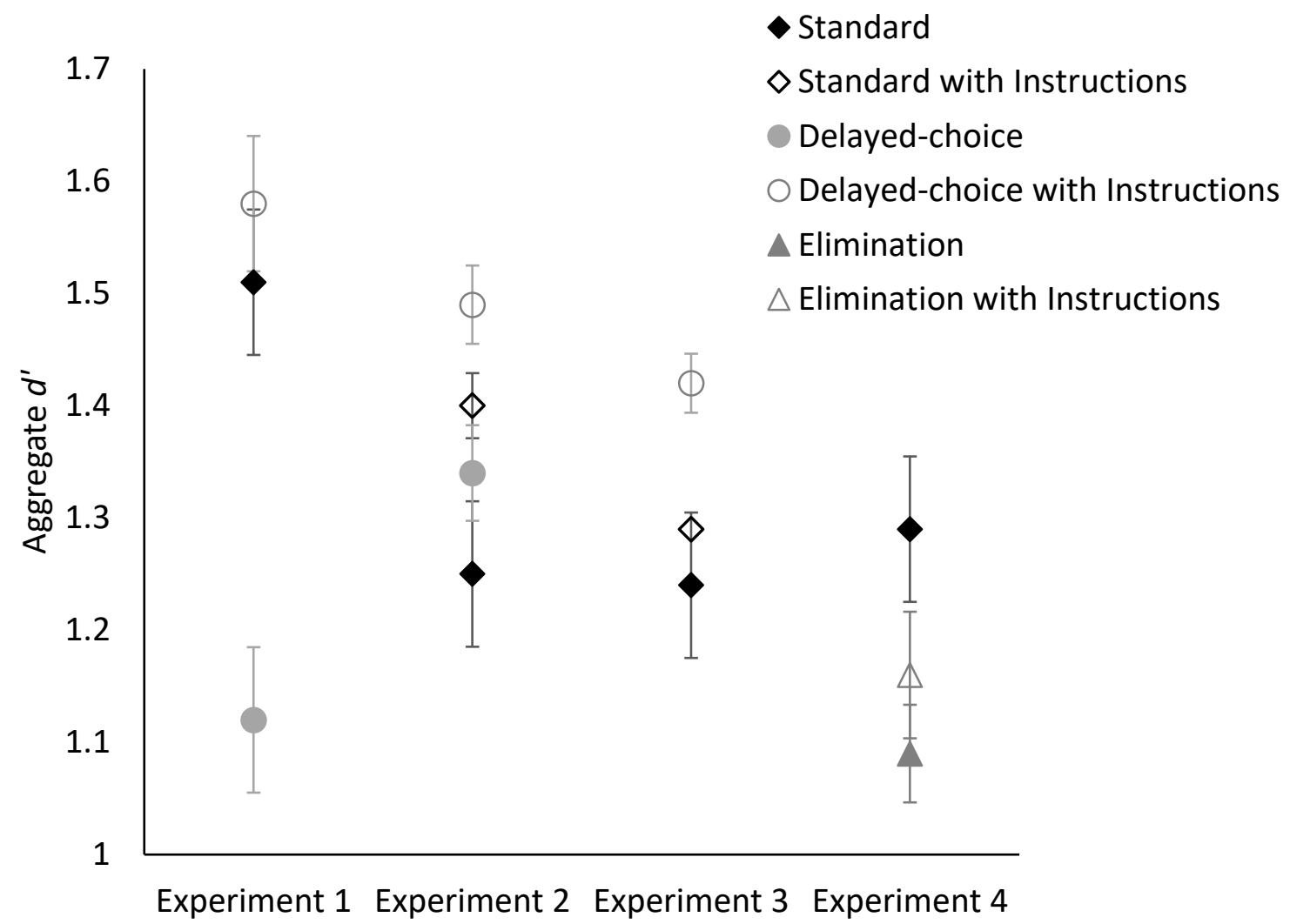

Figure 1. Aggregate $d$ ' by experiment and lineup type, Experiments $1-4^{3}$. Error bars show $95 \%$ confidence intervals.

\footnotetext{
${ }^{3}$ We note that for datasets including multiple participants' responses to multiple stimuli, analyses of aggregate measures can be biased and not appropriately account for shared variability (Judd, Westfall, \& Kenny, 2012).
} 
Standard vs Delayed-choice

(Suspect identifications)

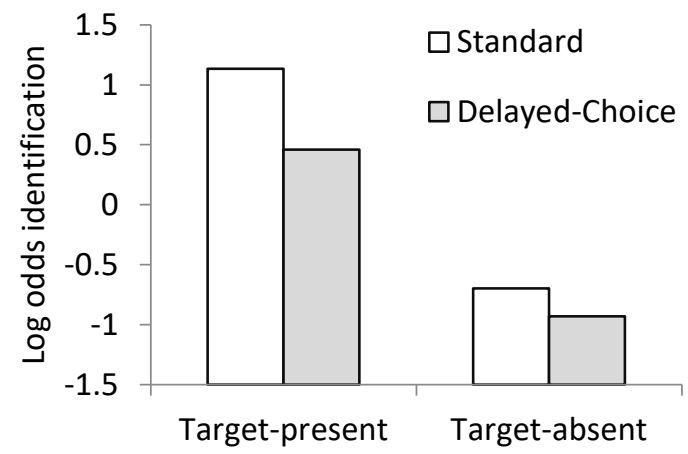

(Choosing)

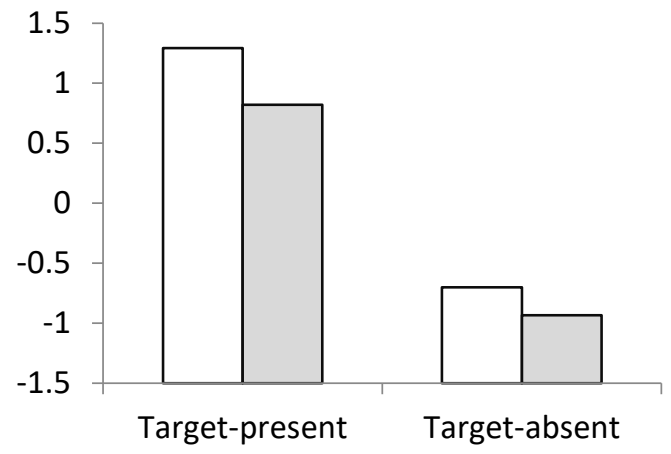

Standard vs Delayed-choice with Instructions

(Suspect identifications)

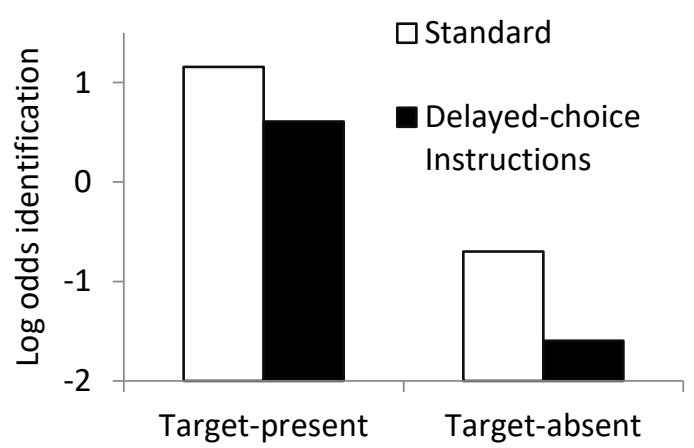

(Choosing)

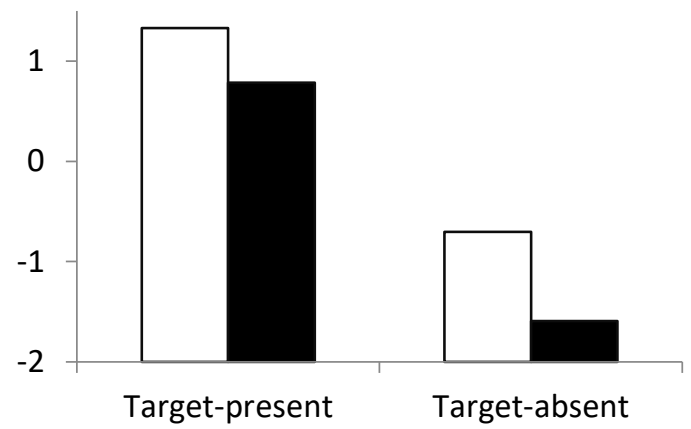

Delayed-choice vs Delayed-choice with Instructions

(Suspect identifications)

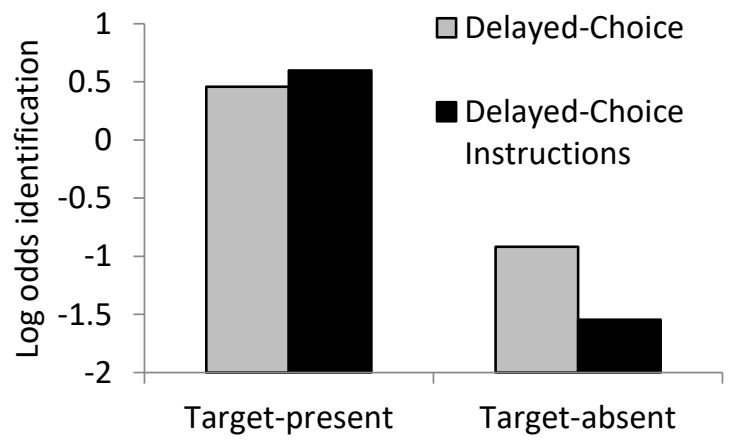

(Choosing)

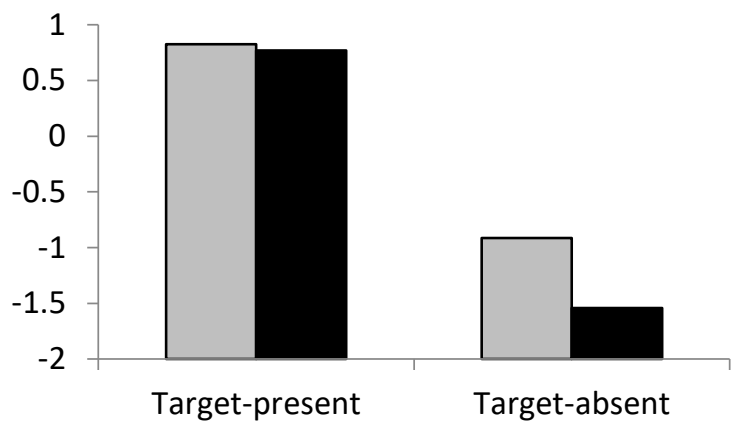

Figure 2. Estimated log odds of identification by lineup type and target presence, Experiment

1. Panels on the left show models predicting suspect identifications and panels on the right show models predicting choosing (including filler selections). Coefficient standard errors presented in Table 2. 
Standard vs Delayed-Choice

(Suspect identifications)

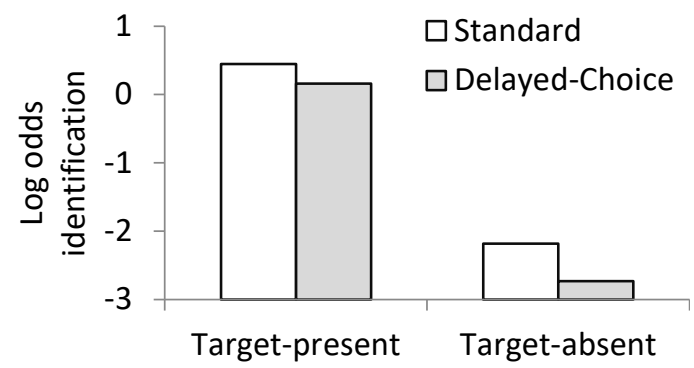

(Choosing)

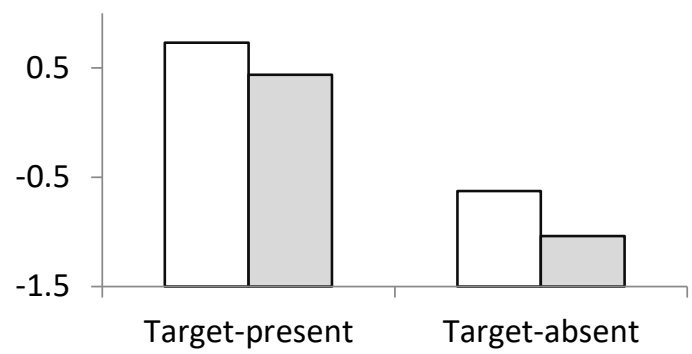

Standard vs Delayed-Choice with Instructions

(Suspect identifications)

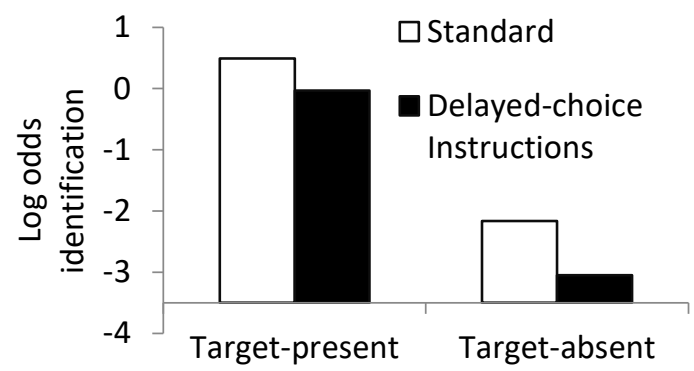

(Choosing)

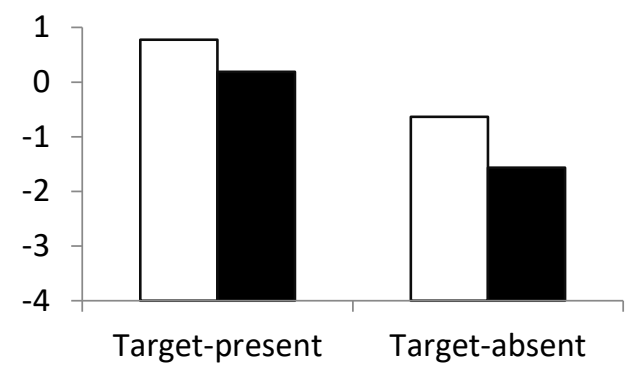

Delayed-Choice vs Delayed-Choice with Instructions

(Suspect identifications)

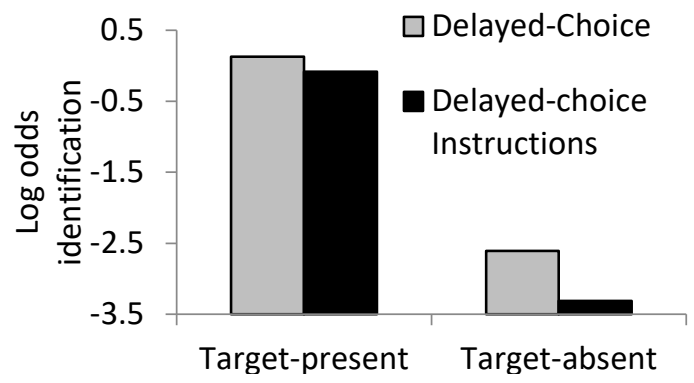

(Choosing)

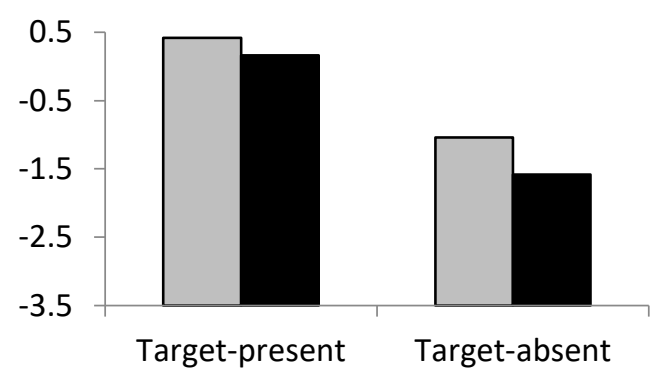

Standard vs Standard with Instructions

(Suspect identifications)

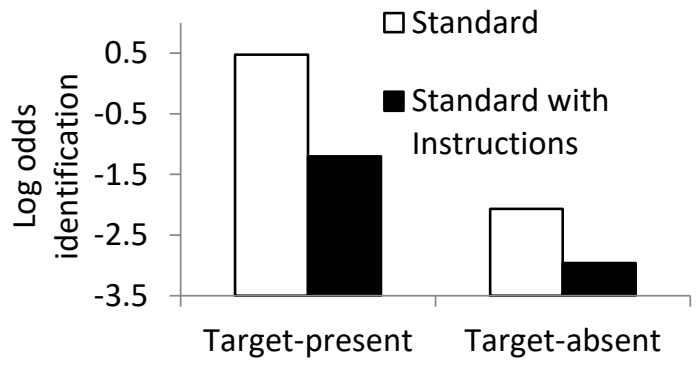

(Choosing)

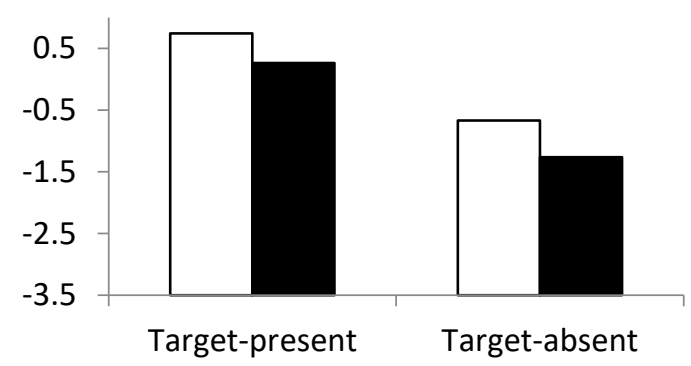


Figure 3. Estimated log odds of identification by lineup type and target presence, Experiment 2. Panels on the left show models predicting suspect identifications and panels on the right show models predicting choosing (including filler selections). Coefficient standard errors shown in Table 4. 
Standard vs Delayed-choice with Instructions

(Suspect identifications)

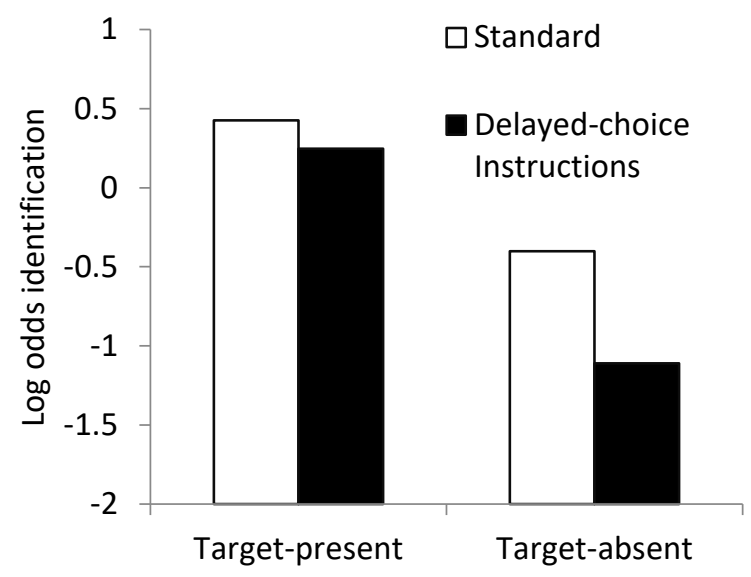

(Choosing)

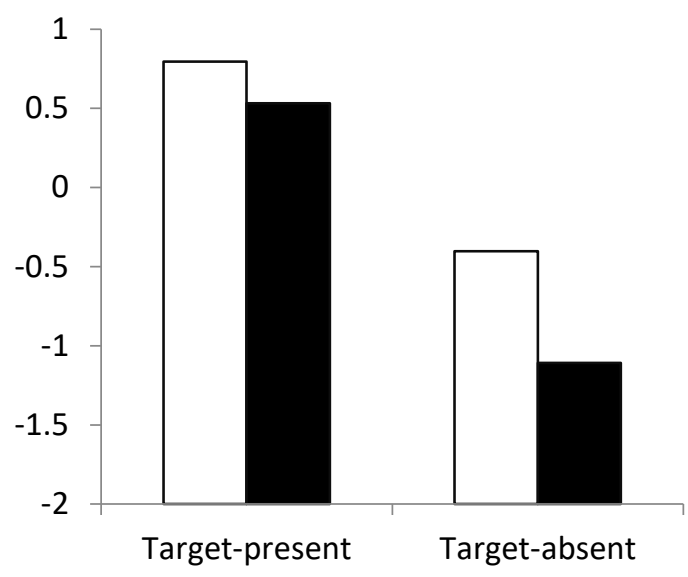

Standard vs Standard with Instructions

(Suspect identifications)

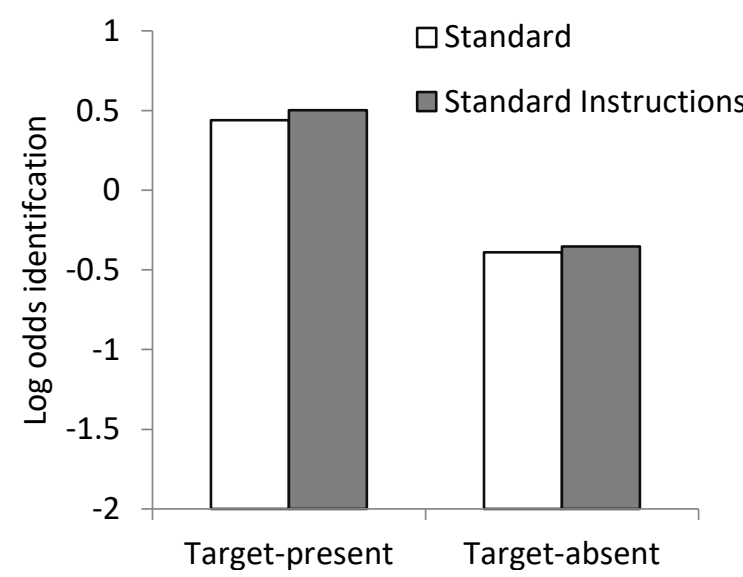

(Choosing)

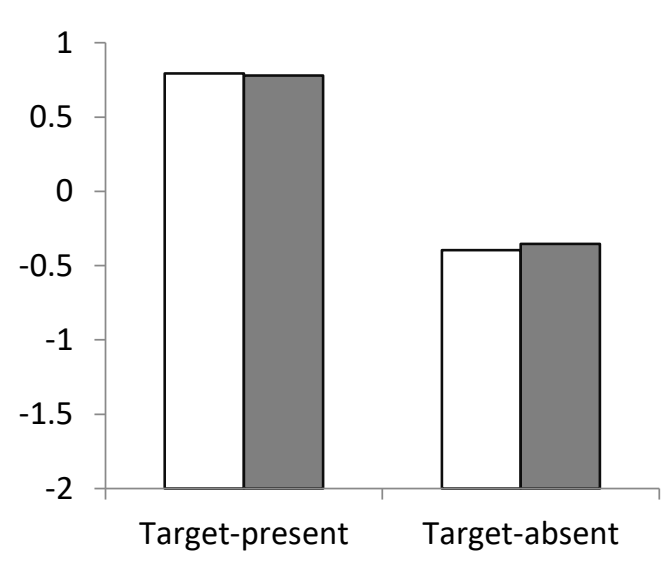

Figure 4. Estimated log odds of identification by lineup type and target presence, Experiment

3. Panels on the left show models predicting suspect identifications and panels on the right show models predicting choosing (including filler selections). Coefficient standard errors are presented in Table 6. 
Standard vs Elimination

(Suspect identifications)

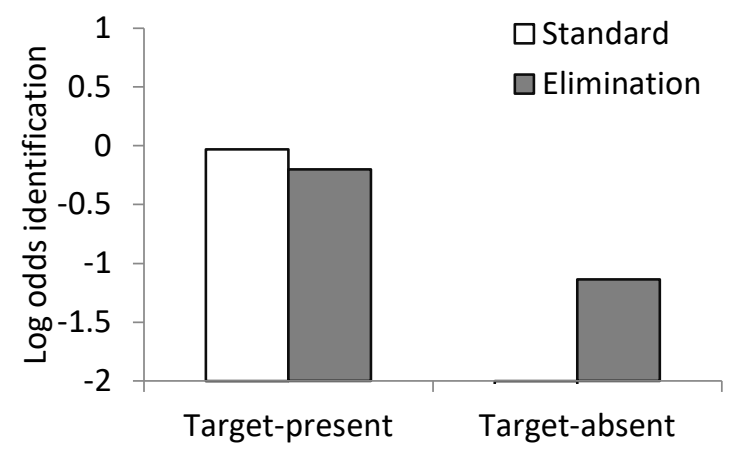

(Choosing)

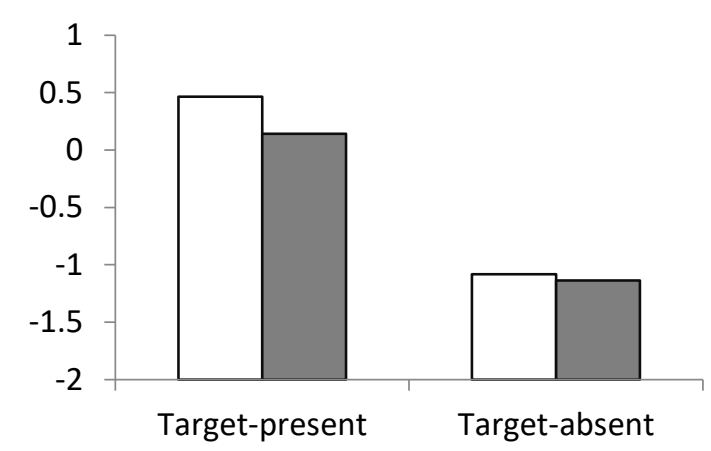

Standard vs Elimination with Instructions

(Suspect identifications)

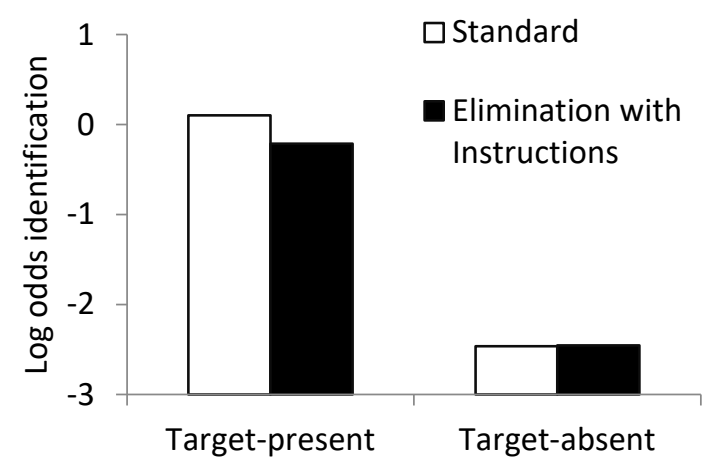

(Choosing)

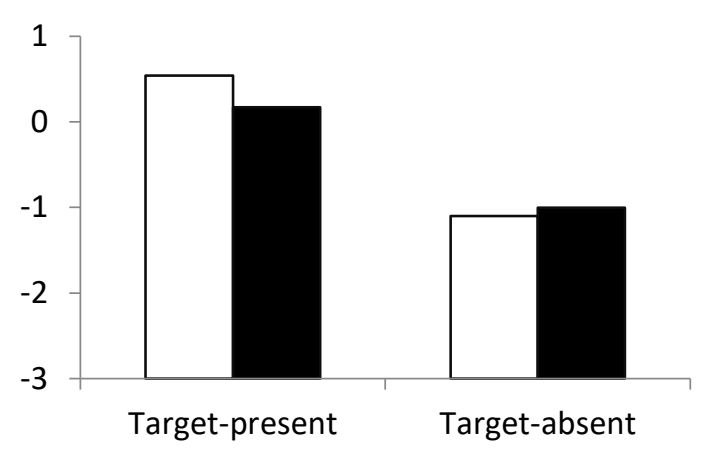

Elimination vs Elimination with Instructions

(Suspect identifications)

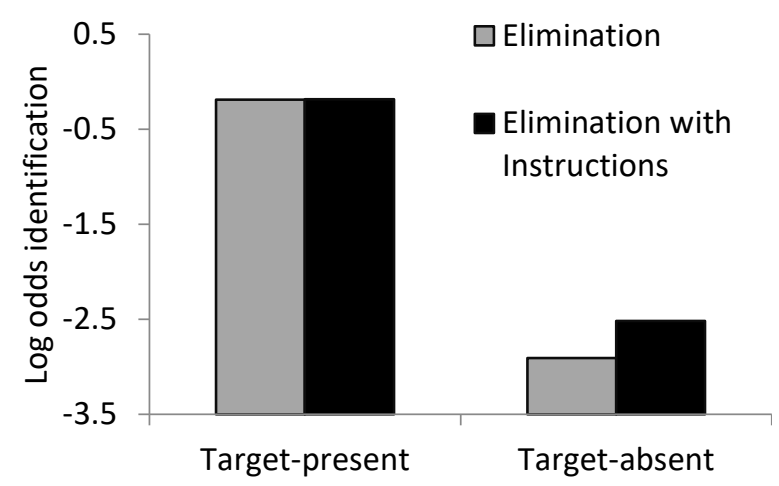

(Choosing)

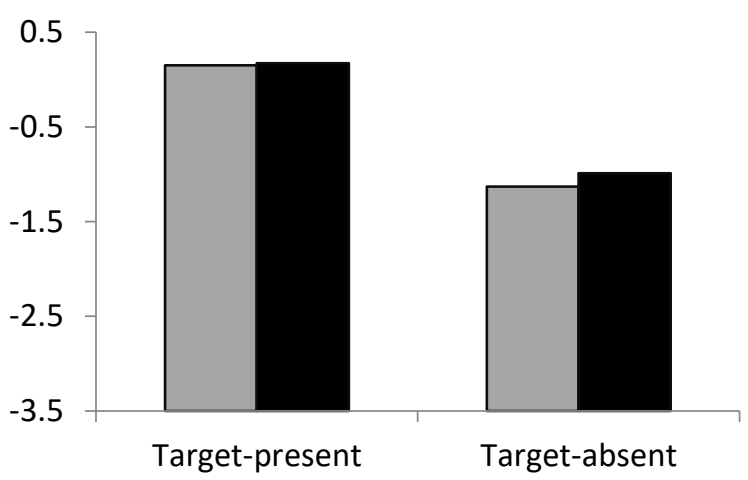

Figure 5. Estimated log odds of identification by lineup type and target presence, Experiment

4. Panels on the left show models predicting suspect identifications and panels on the right show models predicting choosing (including filler selections). Coefficient standard errors for estimates are displayed in Table 8. 
' We found no meaningful difference in response patterns across trials or blocks (e.g., with fatigue) in any of Experiments 1-4, consistent with Mansour et al.'s (2017) results in a multiple lineup trial paradigm. 